\title{
Curve numbers for long-term no-till corn and agricultural practices with high watershed infiltration
}

\section{J.V. Bonta and M.J. Shipitalo}

\begin{abstract}
The Curve Number $(\mathrm{CN})$ method is an engineering and land management tool for estimating surface runoff from rainstorms. We investigated $\mathrm{CN}$ under continuous longterm no-till corn (Zea mays L.; watershed WS191) and compared it with other potentially high infiltration agricultural practices using data from three experimental watersheds (average area $=0.74$ ha $[1.83 \mathrm{ac}])$ at the North Appalachian Experimental Watershed (NAEW) near Coshocton, Ohio. Practices compared were wheat (Triticum aestivum L.) and first- and second-year meadow as part of a 4-year corn-wheat-meadow-meadow rotation (CWMM), continuous meadow, and continuous no-till corn, mulch-tilled corn, and conventionally tilled corn (i.e., moldboard plow). Double-mass curves of runoff for no-till and permanent meadow documented the significant and immediate reduction in runoff from the no-till

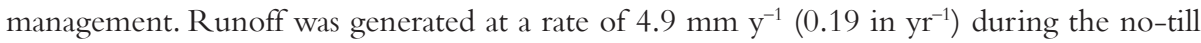

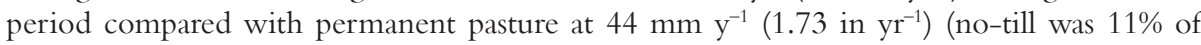
the meadow rate). The asymptotic $\mathrm{CN}$ (CNi) for the 48 -year record of continuous no-till corn practice at WS191 decreased substantially to 66.3 ( $-24.3 \mathrm{CN}$ units) from the period of conventional corn in rotation on the same site. The Natural Resources Conservation Service handbook value for no-till $\mathrm{CN}$ was $16 \mathrm{CN}$ units larger at 82. The larger than expected reduction in $\mathrm{CN}$ was probably due the presence of a thriving earthworm population and numerous earthworm-created macropores that enhance infiltration. The $\mathrm{CN}$ for the mulchtilled corn culture treatment (74.6) was lower than conventional corn (90.6 largest) by 16 $\mathrm{CN}$ units. CN was surprisingly high (77.4) for a watershed in continuous meadow, which was similar to mulch-tilled corn. The wheat years in rotation also had some of the smallest $\mathrm{CN}$ values (63.7), suggesting a smaller $\mathrm{CN}$ for a practice similar to that used in organic agriculture today. Continuous no-till corn had a slightly larger CN (66.3) than meadow (61.9) in the CWMM rotation, suggesting that simple grass establishment can be as effective as longterm no-till to reduce runoff. CN of approximately 60 was the lowest found. The results are applicable for areas of similar terrain, management practices, geology, soils, subsoil permeability, and climate of the NAEW watersheds. Differences between handbook and measured $\mathrm{CN}$ suggest that local values are more representative than handbook values.
\end{abstract}

Key words: conservation tillage-cover crops-earthworms - hay production-meadoworganic agriculture

\begin{abstract}
An environmental goal in agricultural and urban-development enterprises has been to maximize watershed infiltration to minimize problems of flooding, erosion, and degraded water quality. One method of achieving this objective that first became practical in the 1960s with the development of suitable herbicides was the no-till production of row crops that previously had to be cultivated for weed control (Sprague
\end{abstract}

also an ideal environment and food source for earthworms that create macropores by burrowing in the soil. For example, studies by Edwards et al. (1992) in the United Kingdom indicated that average earthworm populations were 2 to 2.5 greater in no-till experimental plots and fields than in comparable tilled areas. Deep burrowing species of earthworms, such as Lumbricus terrestris L., feed on the surface residue and live in noncapillary vertical burrows that can reach a soil depth of more than a meter (Shipitalo 2002). Germann et al. (1984) showed that such macropores are important preferential-flow pathways for rapid infiltration.

At the North Appalachian Experimental Watershed (NAEW) near Coshocton, Ohio, no-till corn (Zea mays L.) has been continuously produced on one watershed since 1964 (Edwards et al. 1988; Shipitalo et al. 2000). A study of macropore diameters and numbers in this watershed after 20 years of no-till corn production showed that there were on average 14,576 pores $\mathrm{m}^{-2}(1,354$ pores $\left.\mathrm{ft}^{-1}\right)>0.4 \mathrm{~mm}$ (0.02 in) in diameter with a mean diameter of 1 to $2 \mathrm{~mm}(0.04$ to $0.08 \mathrm{in})$, and approximately 160 pores $\mathrm{m}^{-2}\left(15\right.$ pores $\left.\mathrm{ft}^{-2}\right)$ with diameters $>5 \mathrm{~mm}$ (0.2 in) that were attributed to burrowing by L. terrestris (Edwards et al. 1988). In total, pores $>0.4 \mathrm{~mm}$ in diameter were reported to comprise $1.4 \%$ of the area. Shipitalo et al. (1994) showed percolation as measured with subsurface pan lysimeters was less in conventionally tilled fields compared with fields in no-till. In another study, Shipitalo et al. (2000) concluded that earthworm burrows in tilled watersheds were less efficient flow paths than those in the no-till watershed. Tillage mechanically disturbed the upper portion of existing macropores and also buried the residue. This reduced the amount of food available to the earthworms, thereby reducing the rate of new burrow formation. In a comparison of their worm-burrow-infiltration field results with similar studies worldwide, Shipitalo and Butt (1999) state that "high infiltration rates can occur in

and Triplett 1986; Triplett and Dick 2008). This practice consists of planting the crop in the previous year's residue, minimizing mechanical disturbance of the soil and using herbicides to control weeds. The residue retained on the soil surface protects it from raindrop impact and decomposes to provide a source of organic matter that increases soil organic carbon (C) levels and enhances soil aggregation. The residue-rich surface is
James V. Bonta is a research hydraulic engineer at the USDA Agricultural Research Service National Sedimentation Lab, Oxford, Mississippi. Martin J. Shipitalo is a research soil scientist at the USDA Agricultural Research Service National Laboratory for Agriculture and the Environment; Soil, Water, and Air Resources Research Unit; Ames, lowa. 
earthworm burrows found in a variety of soils throughout the world and are not limited to the sites we investigated." Another hydrological advantage of the no-till system is the increase in soil $\mathrm{C}$ that improves soil water-holding capacity and infiltration, which can also contribute to a significant decrease in runoff (Hudson 1994).

Field studies at the NAEW no-till site, such as those mentioned above and other macropore studies, primarily focus on within-field and rainfall-simulator investigations, not on runoff generation at the small watershed/ field scale. Watershed runoff potential is often expressed through the widely used Natural Resources Conservation Service (NRCS) curve number (CN). A review of the literature suggests that there are many studies involving models and small-scale studies of no-till systems (Maski et al. 2008), but only one study was found where $\mathrm{CN}$ was determined using runoff data from a no-till watershed (Endale et al. 2011). In this study, the authors used a 33-year runoff record from a 2.7 ha $(6.7 \mathrm{ac})$ watershed in Watkinsville, Georgia, in the Piedmont used to grow no-till soybean (Glycine max L.), sorghum (Sorghum bicolor L.), millet (Pennisetum glaucum L.), cotton (Gossypium hirsutum L.) and corn in the summer, with barley (Hordeum vulgare L.), wheat (Triticum asetivum L.), crimson clover (Trifolium incarnatum L.), and rye (Secale cereale L.) as winter cover crops. The asymptotic method for determining $\mathrm{CN}$ for naturally ordered data (Hawkins 1993) yielded a CN of about 50 with naturally ordered data. However, preliminary $\mathrm{CN}$ results for ordered data were between 55 and 60 (D.M. Endale, personal communication, 2013). Earthworms were observed in the no-till watershed, but population density was not measured. In nearby no-till plots, however, Lumbricus rubellus and Aporrectodea spp. were the primary species found, whereas Microscolex spp. were the most frequently collected earthworms in conventionally tilled plots. Additionally, worm populations were greater in no-till (average of 274 worms $\mathrm{m}^{-2}$ [25.5 worms $\left.\mathrm{ft}^{-2}\right]$ ) than in conventionally tilled plots (50 worms $\mathrm{m}^{-2}$; Weyers et al. 2008; D.M. Endale, personal communication, 2013). Fertilization with poultry litter further increased the earthworm populations in the no-till plots from an average of 229 to 319 worms $\mathrm{m}^{-2}$ (21.3 to 29.6 worms $\mathrm{m}^{-2}$ ).
Runoff reduction is important for maintaining a stable agricultural production enterprise (conventional and organic), particularly in the sloping lands found in the Appalachian region (slopes typically $\sim 12 \%$ to $25 \%$ ). Management practices that increase soil $\mathrm{C}$ and residue cover in general will decrease soil erosion and flood flow frequency, improve water quality, and increase productivity. Other long-term NAEW data are also available from experimental watersheds managed with practices that are potentially as effective in enhancing infiltration on sloping lands as no-till, such as watersheds used for hay production and in crop rotations. Therefore, our objective was to document the runoff-reducing benefits of long-term no-till corn using the NRCS CN method and to compare the results with other agricultural practices that enhance infiltration. The approach was exploratory and statistical and used available runoff, precipitation, soil, and land management data dating to the establishment of the NAEW in the late 1930s through 2011. Where data were readily available, CN was compared with other practices on the watersheds that yielded more runoff to provide a measure of runoff reduction due to the high infiltration practices.

\section{Materials and Methods}

Watershed Physical Characteristics. The monitored watersheds were on the NAEW facility in east central Ohio near Coshocton. Three small upland experimental watersheds chosen for study are (figure 1) WS128 (1.08 ha $[2.67 \mathrm{ac}])$, WS130 (0.66 ha $[1.63 \mathrm{ac}])$, and WS191 (0.49 ha [1.21 ac]). The soils in these watersheds were formed in residuum derived from nearly flat-lying shale, sandstone, clay, and coal of the Middle Pennsylvanian, Allegheny Formation. Average slopes were large, ranging from $9.4 \%$ (WS191) to $21.7 \%$ (WS130). In this landscape, runoff concentrates in swales without well-defined channels. Runoff is ephemeral and of relatively short duration as a result of heavy rainfall or snow melt, under wet antecedent soil conditions. Average annual precipitation is $959 \mathrm{~mm}$ (38 in), and the average annual temperature is $10.4^{\circ} \mathrm{C}\left(50.7^{\circ} \mathrm{F}\right)$. High intensity storms that generate the largest runoff rates occur mostly from June through August.

Five soil series were identified in these watersheds in a first-order soil survey conducted by the NRCS (Kelley et al. 1975) (table 1). These soil series are moderately well to well drained with moderately slow to rapid permeabilities. The soils mapped in WS130 suggest that it has potentially higher infiltration capabilities than the other two watersheds. More detailed soils information can be found in Kelley et al. (1975).

Agricultural Management Histories. Since the NAEW was established in 1935, small experimental uniformly treated watersheds have been used to test the effectiveness of various agricultural management practices to control runoff and erosion. WS191 was selected because of its long runoff record of continuous no-till corn (48 years starting in 1964; table 2 and figure 1). Furthermore, an assessment of the effect of tillage on earthworm populations on NAEW watersheds indicated that the greatest number of earthworms and the most diverse populations occurred with no-till management (Bohlen et al. 1995). Additionally, an examination of the data from this site suggested there was a drastic decrease in runoff due to this practice compared with conventionally tilled other NAEW runoff records. Prior to the implementation of no-till, WS191 was in a 4-year corn-wheat-meadow-meadow (CWMM) rotation with mostly conventional tillage. There were significant gaps in the runoff record during this period, resulting in insufficient numbers of runoff events to compute $\mathrm{CN}$ for some crop years (table $2)$. This included the first- and second-year meadow (M1 and M2, no grazing) in the CWMM rotation, practices that potentially cause high infiltration rates, with which the no-till crop years were to be compared. As an alternative, the runoff record for WS128 (adjacent to WS191) was found to be suitable to explore some of the agricultural practices, although the runoff record for this watershed ended in 1972. To evaluate the recent data from WS191 and compare it with another potentially high infiltration site, WS130 was selected because it has been in continuous meadow (hay production, typically one or two hay harvests per year, no grazing) from 1938 through 2011, with runoff monitored during most of this time (table 2).

The CWMM rotation began in 1944 at WS191 and in 1945 in WS128; the rotational sequences were offset by one year to evaluate the practices during different weather years. Part of the CWMM watershed experiments included evaluating conventional corn (moldboard plow to $\sim 18 \mathrm{~cm}$ (7 in) and soil surface tillage for soil crust and weed control at WS191). At WS128, a corn- 


\section{Figure 1}

Topographic maps, soils, and instrumentation for (a) WS128, (b) WS130, and (c) WS191 (map inset shows location on the North Appalachian Experimental Watershed [NAEW]). Dashed lines are soil boundaries, black dots are soil sampling sites (Kelley et al. 1975).
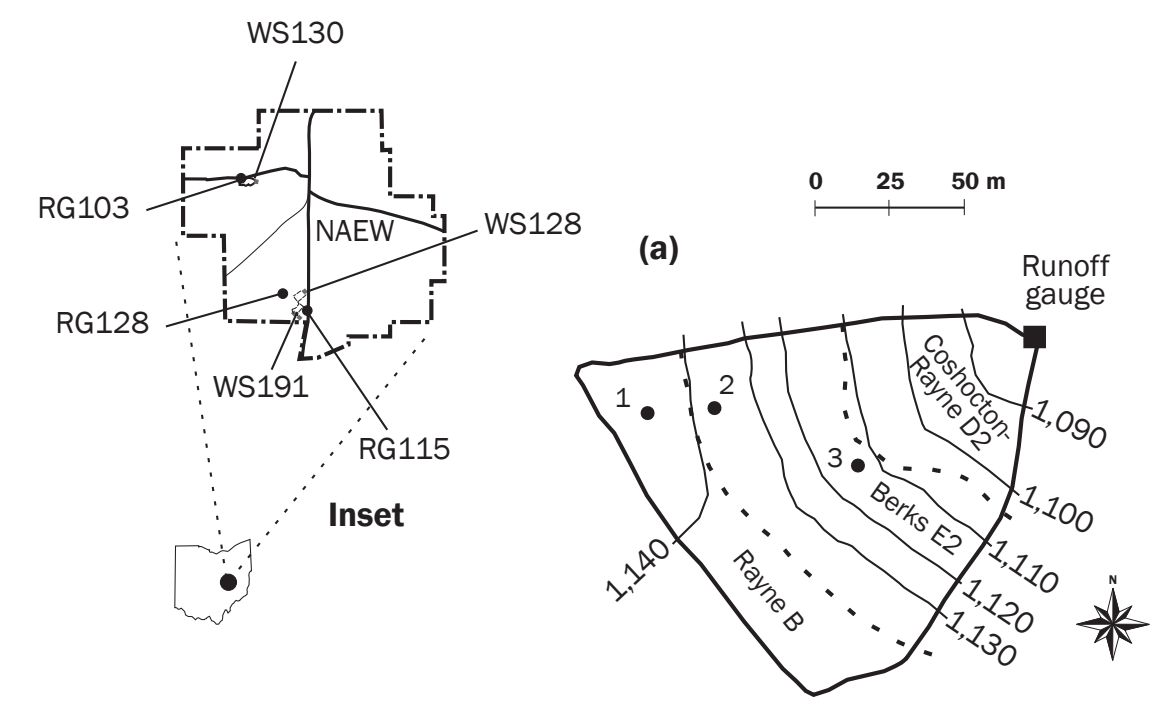

(b)

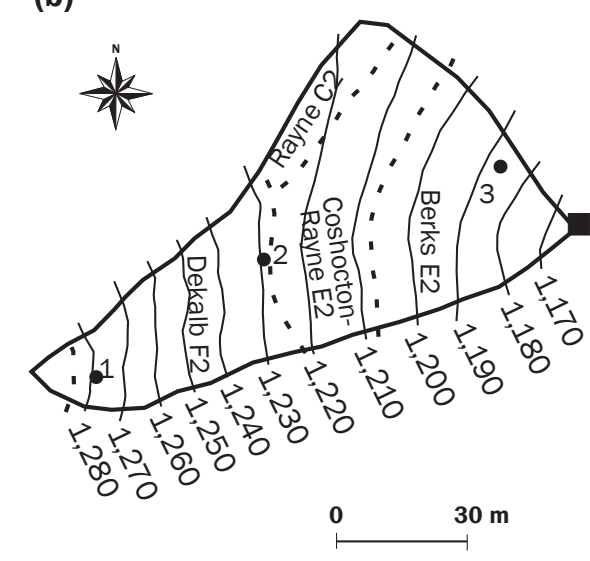

(c)

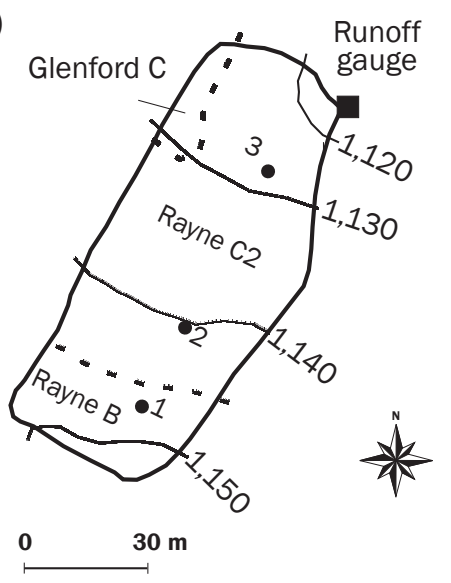

mulch culture or mulch-till practice, which was defined as "manure and sod partly incorporated with an orchard disk" using sod as mulch, was evaluated. This is compared with the "prevailing practice" defined as "manure and sod turned under with moldboard plow" (USDA SCS 1944). The degrees of soil disturbance and protective residue left on the soil surface are factors contributing to potential differences in runoff for these two practices. The runoff- and erosion-reducing benefits of the corn-mulch culture practice were documented in the 1944 annual report (USDA SCS 1944).

At WS191, other corn management practices were tested in the rotation, however, there were only sufficient runoff data for the prevailing practice to determine $\mathrm{CN}$. Wheat was usually sown in October following corn harvest and was harvested the following year in August. Grass was undersown into the wheat in April in order to establish meadow the following year. Manure was applied during the growing season and served as mulch and for establishing a good understory of clover (USDA SCS 1944). Manure supplied nutrients during most years at WS128 (similar to organic agriculture); however, during some CWMM years, mineral fertilizer was used. Lime was applied occasionally as needed. The wheat had sufficient growth at harvest to minimize runoff, and the manured meadow had sufficient cover to protect the soil (USDA SCS 1948). A reference to "no-till" in the present paper implies long-term continuous no-till corn with an

Table 1

Mapped soil characteristics (Kelley et al. 1975).

\begin{tabular}{|c|c|c|c|c|c|c|c|c|}
\hline \multirow{2}{*}{$\begin{array}{l}\text { Soil series* } \\
\text { Berks } \\
\text { (Rigley-Dekalb) }\end{array}$} & \multirow{2}{*}{$\begin{array}{l}\begin{array}{l}\text { Hydrologic } \\
\text { soil group }\end{array} \\
A-B\end{array}$} & \multirow{2}{*}{$\begin{array}{l}\begin{array}{l}\text { Available } \\
\text { water capacity }\end{array} \\
\text { Low }\end{array}$} & \multirow{2}{*}{$\begin{array}{l}\begin{array}{l}\text { Soil } \\
\text { drainage }\end{array} \\
\text { Well }\end{array}$} & \multirow{2}{*}{$\begin{array}{l}\text { Parent } \\
\text { Material }\end{array}$} & \multirow{2}{*}{$\begin{array}{l}\text { Permeability } \\
\text { Moderately } \\
\text { rapid }\end{array}$} & \multirow{2}{*}{$\begin{array}{l}\begin{array}{l}\text { Permeability } \\
\left(\mathbf{m m ~ h}^{-1}\right) \dagger\end{array} \\
5 \text { to } 15\end{array}$} & \multicolumn{2}{|c|}{$\begin{array}{l}\text { Depth range } \\
\text { to bedrock }(\mathrm{cm})\end{array}$} \\
\hline & & & & & & & 51 & 102 \\
\hline $\begin{array}{l}\text { Coshocton-Rayne } \\
\text { (Gilpin) }\end{array}$ & C & Medium & $\begin{array}{l}\text { Moderately } \\
\text { well }\end{array}$ & $\begin{array}{l}\text { Siltstone, } \\
\text { silty shales }\end{array}$ & Slow/moderate & 1 to 7 & 102 & 183 \\
\hline Dekalb & $A$ & Low & Well & Sandstone & Rapid & 15 to 30 & 86 & NAf \\
\hline Glenford & $\mathrm{C}$ & High & $\begin{array}{l}\text { Moderately } \\
\text { well }\end{array}$ & $\begin{array}{l}\text { Deep silty } \\
\text { deposited by } \\
\text { wind and water }\end{array}$ & $\begin{array}{l}\text { Moderately } \\
\text { slow }\end{array}$ & 1 to 5 & 60 & NA \\
\hline $\begin{array}{l}\text { Rayne } \\
\text { (Gilpin) }\end{array}$ & $\mathrm{C}$ & Medium & Well & $\begin{array}{l}\text { Shale siltstone, } \\
\text { sandstone }\end{array}$ & Moderate & 2 to 5 & 102 & 183 \\
\hline
\end{tabular}

* Newer county soil series name in parentheses.

† Depth-weighted average of Natural Resources Conservation Service standard quantification of permeability in approximate top 1 m soil depth (Kelley et al. 1975).

$\ddagger N A=$ not available. 
Table 2

Watershed characteristics, runoff and agricultural management records, and sample sizes for the three watersheds.

\begin{tabular}{|c|c|c|c|c|c|c|c|c|c|c|}
\hline \multirow[b]{2}{*}{ Watershed } & \multirow[b]{2}{*}{$\begin{array}{l}\text { Area } \\
\text { (ha) }\end{array}$} & \multirow[b]{2}{*}{$\begin{array}{l}\text { Slope } \\
(\%)\end{array}$} & \multirow[b]{2}{*}{$\begin{array}{l}\text { Range of } \\
\text { years of } \\
\text { runoff record }\end{array}$} & \multirow[b]{2}{*}{$\begin{array}{l}\text { Major gaps } \\
\text { in runoff } \\
\text { record }\end{array}$} & \multirow[b]{2}{*}{$\begin{array}{l}\text { Approximate } \\
\text { land } \\
\text { management } \\
\text { dates }\end{array}$} & \multirow[b]{2}{*}{$\begin{array}{l}\text { General } \\
\text { land use }\end{array}$} & \multirow[b]{2}{*}{$\begin{array}{l}\text { Agricultural } \\
\text { practice for } \\
\text { corn years }\end{array}$} & \multicolumn{3}{|c|}{ Runoff event summary } \\
\hline & & & & & & & & $\begin{array}{l}\text { General } \\
\text { land } \\
\text { management }\end{array}$ & $\begin{array}{l}\text { Number } \\
\text { of } \\
\text { runoff } \\
\text { events }\end{array}$ & $\begin{array}{l}\text { Number } \\
\text { of runoff } \\
\text { events } \\
\text { selected }\end{array}$ \\
\hline \multirow[t]{4}{*}{128} & \multirow[t]{4}{*}{1.08} & \multirow[t]{4}{*}{13.6} & \multirow[t]{4}{*}{1945 to 1972} & 1947 to 1950 & \multirow[t]{4}{*}{1945 to 1972} & \multirow[t]{4}{*}{ CWMM } & \multirow{5}{*}{$\begin{array}{l}\text { Mulch culture } \\
\text { ("corn-m") }\end{array}$} & Corn-mulch culture & 49 & 41 \\
\hline & & & & 1950 to 1954 & & & & Meadow 1 & 61 & 35 \\
\hline & & & & 1954 to 1958 & & & & Meadow 2 & 43 & 23 \\
\hline & & & & & & & & Wheat & 77 & 35 \\
\hline 130 & 0.66 & 21.7 & 1938 to 2011 & 1971 to 1972 & 1938 to 2011 & $\begin{array}{l}\text { Continuous } \\
\text { meadow }\end{array}$ & & $\begin{array}{l}\text { Permanent } \\
\text { meadow }\end{array}$ & 499 & 247 \\
\hline \multirow[t]{4}{*}{191} & \multirow[t]{4}{*}{0.49} & \multirow[t]{4}{*}{9.4} & \multirow[t]{4}{*}{1944 to 2011} & 1948 to 1952 & 1944 to 1963 & CWMM & Conventional & Corn & 15 & 15 \\
\hline & & & & 1954 to 1956 & 1964 to 2011 & $\mathrm{C}$ & No till & Wheat & 29 & 15 \\
\hline & & & & 1957 to 1960 & & & & No-till & 68 & 47 \\
\hline & & & & 1972 to 1979 & & & & & & \\
\hline
\end{tabular}

Notes: CWMM = corn-wheat-meadow-meadow rotation. $\mathrm{C}$ = corn; no grazing during meadow years.

earthworm population, and a reference to "wheat" is wheat in a CWMM rotation.

Data. Runoff was measured using Parshall flumes and $\mathrm{H}$ flumes (Brakensiek et al. 1979). Runoff record lengths began about the time of NAEW establishment and ended on different dates (table 2). There were gaps in the records as watersheds and rain gauges were taken in and out of operation. Consequently, the durations of runoff records varied and may not have overlapped with some agricultural practices (table 2).

Precipitation was measured at three gauges adjacent to the watersheds: RG115 and RG128 for WS128 and WS191 (inset in figure 1) and RG100 for WS130 using standard weighing bucket rain gauges. All gauges were within $\sim 200 \mathrm{~m}(656 \mathrm{ft})$ of a watershed boundary. Precipitation records were composited for WS128 and WS191 where there were gaps by duplicating the missing record from RG115 and RG128 $(\sim 350 \mathrm{~m}[1,148 \mathrm{ft}]$ apart) . These records were identified as RG628 and RG691 for WS128 and WS191, respectively. Compositing rainfall records allowed maximum use of available runoff data because there were gaps in the precipitation when runoff data were available.

Watershed runoff and precipitation data were tabulated in breakpoint form with a time resolution of one minute and depth resolutions of $0.3 \mathrm{~cm}(0.01 \mathrm{ft})$ gauge height for runoff and $0.25 \mathrm{~mm}$ (0.01 in) for precipitation. Runoff charts were hand tabulated through about 1990, after which data loggers were installed to record runoff, and the data were computer processed.
Soil water characteristic data were obtained from soil samples taken in the three locations (black dots labeled 1 through 3 in figure 1) in each watershed (Kelley et al. 1975). Available soil water vs. tension data from Kelley et al. (1975) are summarized in the Results and Discussion section by plotting median percentage volume against soil tension for three soil depths to help explain some results.

Defining Rainfall-Runoff Events. Runoff event depths $(Q)$ corresponding to causal precipitation $(P)$ were identified using the program, GETPQ96 (Dripchack et al. 1996), for the available periods of runoff. The program extracts only the larger runoff events (peak runoff greater than $0.025 \mathrm{~mm}$ $\mathrm{h}^{-1}\left[0.001\right.$ in $\left.\left.\mathrm{hr}^{-1}\right]\right)$. Additionally, because the CN method is a rainfall-runoff model, only events occurring from April through October were used to minimize inclusion of snowmelt-generated runoff. Any snowmelt events that did occur during this period were also omitted from the analyses. Events were then associated with a period of land management within a watershed, and $P$ and $Q$ were used to compute CNs.

Computing Curve Numbers. The NRCS CN method (USDA SCS 1972) is widely used throughout the world to model runoff depths from watersheds. $\mathrm{CN}$ is a parameter that quantifies the runoff potential of watersheds and is a function of watershed land use and vegetation and soil characteristics. The basic equation to compute runoff depth in the NRCS CN method is

$$
\begin{array}{r}
\mathrm{Q}=\frac{(\mathrm{P}-0.2 \mathrm{~S})^{2}}{\mathrm{P}+0.8 \mathrm{~S}} P>0.2 \mathrm{~S} \\
\mathrm{Q}=0 \quad P \leq 0.2 \mathrm{~S},
\end{array}
$$

where $Q=$ total direct runoff volume, $\mathrm{P}=$ causal rainfall, and $S=$ potential maximum watershed retention abstraction (all variables have length units of millimeters in the present paper). Furthermore, equation 1 assumes that the initial watershed abstraction of rainfall $(I a)$ is a function of $S$ as

$I a=0.2 \mathrm{~S}$.

The variable $S$, which varies with antecedent soil moisture and other variables, is converted to a $\mathrm{CN}$ through the relation

$C N=25,400 \div(254+S)$.

Equation 3 constrains the $\mathrm{CN}$ in a range between 0 and 100, with higher CNs associated with higher watershed runoff potential (e.g., urbanized areas). Most CNs vary between 55 and 98 .

There are many methods for determining $\mathrm{CN}$; however, the ordered asymptotic method was used with event $P$ and $Q$ data (Hawkins 1993). Briefly, in this method the P-Q event pairs are separated, $P$ and $Q$ are ordered separately, and then ordered $P$ and $Q$ data are merged. The $P$ and $Q$ data will not likely be naturally paired after ordering and merging; however, the $P$ and $Q$ data will have the same frequencies of occurrence, an assumption made in engineering application. Ordered data were used instead of the natural data because pre- 
liminary plotting of the data suggested that variability of $C N$ vs. $P$ data was considerably reduced using the ordered approach. A comparison of results using ordered and natural data is beyond the scope of the present study. However, there were visual differences in plots, and further study comparing the two approaches is a general research need. Hawkins et al. (2009) mentioned that the ordered approach yields larger $\mathrm{CN} i$ than the natural data approach. The results will be affected by the approach used and will incorporate any bias due to methodology.

After merging, watershed storage is computed using (Hawkins et al. 2009)

$S=5\left[P+2 Q-\left(4 Q^{2}+5 P Q\right)^{0.5}\right]$,

and $\mathrm{CN}$ is determined using equation 3. Equation 4 is equation 1 solved for $S$. CN is then plotted against the corresponding ordered $P$ leading to a trend of decreasing $\mathrm{CN}$ as $P$ becomes larger. Hawkins (1993) suggested the data should be fitted to

$C N=C N i+(100-C N i) \mathrm{e}^{-\mathrm{kP}}$,

where $\mathrm{CN} i$ is the asymptotic $\mathrm{CN}$, and $k$ is a fitting parameter that quantifies the rate at which $\mathrm{CN}$ approaches $\mathrm{CNi}\left(\mathrm{mm}^{-1}\right)$. A larger $k$ results in a $C N i$ applicable to smaller $P$ and vice versa. The $C N i$ is the runoff potential of the watershed for large rainfalls and is a function of the limiting interaction of vegetation, land management, and surface and subsurface soil and percolation characteristics for large P. The two parameters were determined using nonlinear regression (implemented as proc nlin, SAS Institute 2012). An enveloping CNo is typically plotted on an asymptotic graph of CN vs. P. CNo is the curve of zero runoff when $P=0.2 S$. CN cannot plot below this line because the $\mathrm{CN}$ method assigns $Q=0$ when $P=0.2 S$ (equation 1 ). CNo is determined by

$C N_{o}=25,400 \div(254+P \div 0.2)$

Because equation 5 decays exponentially, a measure of a minimum precipitation above which $\mathrm{CNi}$ is applicable was computed at the point where $99 \%$ of the $C N i$ is reached:

$P_{\text {min }}=\ln (0.01) \div-k$.

The effectiveness of no-till to reduce runoff resulted in few runoff events. Therefore, in order to investigate a possible trend in $\mathrm{CN} i$ as no-till matured, time intervals in the no-till period at WS191 were identified by trial and error so that a sufficient number of events in each interval enabled a reasonable estimate of $C N i$ while minimizing the length of each period to maximize the number of periods. Rank correlation probability was computed to determine whether a trend in CNi was apparent with period.

Curve Number Comparisons. The CN fittings for periods of constant land use within a watershed in table 2 were compared using the sum-of-squares-reduction test (Hinds and Milliken 1987; SAS Institute 2012), a nonlinear analysis of covariance. This procedure assesses the difference in $\mathrm{CN} i$ and $k$ for each land management. Two underlying models comprise this method, one is fitting equation 5 to all data regardless of land management (to determine whether there are overall differences between land management types), and the other uses equation 5 to compute the parameters individually when differences are found in the first test. The former model is termed the combined model, and the latter is termed the full model because fitting is performed for each land management and there are more parameters. The method fits the two models simultaneously for each land management by using a difference in the parameters.

$\mathrm{CN} i$ for three land management types is formulated as a difference from the main fitting parameter $\left(\mathrm{CN}_{1}\right.$ here $)$ as

$$
\begin{aligned}
& C N i L M_{1}=C N i_{1} \text { for } L M_{1} \\
& C N i L M_{2}=C N i_{1}+C N i d_{2} \text { for } L M_{2} \\
& C N i L M_{3}=C N i_{1}+C N i d_{3} \text { for } L M_{3},
\end{aligned}
$$

where $\mathrm{LM} i=\mathrm{a}$ classification variable for land management practice $i$, such as no-till, wheat, etc. $\mathrm{CNid}_{2}$ and $\mathrm{CNid}_{3}$ are differences from $\mathrm{CNi}_{1}$ (e.g., the difference $\mathrm{CNid}_{2}$ is between the parameter $C N i_{1}$ in equation 8 for $L M_{1}$ and $C N i L M_{2}$ for $L M_{2}$ in equation 9). If zero lies between upper and lower confidence limits (alpha $=0.05)$, then there is no difference in a parameter compared with $\mathrm{CNi}_{1}$ (e.g., $\mathrm{CNid}_{2}$ is not significantly different from zero). If zero lies outside of the confidence interval, then $C N i_{1}$ is different from $\mathrm{CNi}_{2}$ for the land management being considered (e.g., $\mathrm{CNi}_{2}=\mathrm{CNi}_{1}+$ $\mathrm{CNid}_{2}$ ). The estimated parameters from the method are $\mathrm{CNi}_{1}, \mathrm{CNid}_{2}$, and $\mathrm{CNid}_{3}$ (if two treatments are considered, then $\mathrm{CNiLM}_{3}$ and $\mathrm{CNid}_{3}$ do not enter the analysis). The final parameters are computed from equations 9 and 10. The same procedure is applied to determine whether the $k$ parameter is significantly different, and its test is performed simultaneously with $C N i$. Tables of results contain the standard error, confidence limits, and fitted and final parameter estimates. The same procedure was followed for comparisons across watersheds, using pooled agricultural practice data.

Where no significant differences were found, a combined curve was recomputed by combining the separate land management data sets. The $\mathrm{CN}$ differences in similar agricultural management practices were also compared across watersheds using the sumof-squares-reduction test.

More importance was placed on whether there were significant differences in $\mathrm{CN} i$ than $k$. This is because the trend of points in the $C N-P$ system appears to be modeled well using equation 5 . To date there is no theoretical basis for equation 5 , and $k$ is only a fitting parameter; however, $k$ dictates the rate at which $\mathrm{CN}$ approaches $\mathrm{CNi}$ and is used to compute $P_{\min }$. $\mathrm{CN} i$ values and combinations are summarized at the end.

$\mathrm{CN}$ statistics using natural (unordered) data were also computed from runoff events with $\mathrm{P}>25 \mathrm{~mm}$ (0.98 in) (using all events skews the CN statistics). The minimum, maximum, and median $\mathrm{CN}$ were computed for uncombined land management practices and compared with the asymptotically computed values in the summary table.

Double-Mass Curves of Runoff. Changes in runoff from WS191 were shown by plotting a double-mass curve of accumulated daily runoff from WS191 and WS130. WS130 is the only NAEW watershed on which the land management did not change and for which there was a runoff record during most of the no-till period in WS191. Visually, the nonresponsiveness of WS191 (flat accumulated runoff trend) compared with potentially high infiltration meadow practice on WS130 to the same storms is a measure of the effectiveness of the no-till practice using all runoff data. A similar analysis for WS191 and daily precipitation from RG691 was only summarized in the results. Total runoff production and precipitation for RG691, WS191, and WS130 were computed as differences from the mass curves for 
the two land management periods. Ratios of corresponding runoff production and precipitation depths were compared as a measure of the effect of no-till on runoff (mm runoff $\mathrm{y}^{-1}$ and $\mathrm{mm}$ runoff at WS191 / mm runoff at WS130). Tick marks on the double-mass graph show the beginning of calendar years. Data were only plotted if they were simultaneously monitored at the two sites to avoid gaps in the record that would confound interpretation of the graph. Also, snowmelt data were included in this analysis, unlike for the CN method.

\section{Results and Discussion}

Event Data Summary for Determining Curve Number. Total numbers of runoff events for the various land-management and watershed combinations ranged from 15 (WS191-corn) to 499 (WS130-permanent meadow; table 2). After selecting for events occurring from April through October, sample sizes were unchanged for WS191-corn and reduced to 247 for WS130-permanent meadow. Visual inspection of the selected events on a $C N$ vs. $P$ plot suggested that a reliable CNi asymptote could be computed for the number of events and data available.

Double-Mass Curve of Runoff. Prior to 1964, the year when no-till was established, runoff accumulated at similar rates in both WS191 and WS130 (approximately 14.2 and

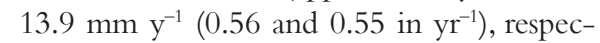
tively). Both watershed accumulations were nearly identical for simultaneously monitored periods ( 300 mm (11.8 in) each; figure 2).

During the no-till period starting in 1964 , $192 \mathrm{~mm}$ (7.56 in) of runoff was measured at WS191 over the $~ 35$-year runoff record within the $\sim 48$ years of no-till on the watershed, a substantially lower average rate of 4.9 $\mathrm{mm} \mathrm{y}^{-1}\left(0.19\right.$ in $\left.\mathrm{yr}^{-1}\right)$. Two large February runoff events in 1971 and 2004 (larger increases in the mass curve in figure 2) were due to snowmelt and/or frozen soil. These events contributed between $80 \%$ and 100\% of the annual runoff amounts and accounted for approximately half of the runoff measured during no-till. Runoff at WS130 was

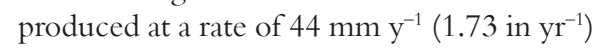
during the WS191 no-till period-WS191 runoff production rate was only $11 \%$ of WS130 runoff.

The ratio of runoff production to precipitation was reduced six-fold by no-till management (i.e., runoff was $3 \%$ of precipitation prior to no-till and $0.49 \%$ of

\section{Figure 2}

Double-mass curve of daily runoff for WS191 (no-till corn) and 130 (meadow). Vertical ticks mark the beginning of years within decades shown.

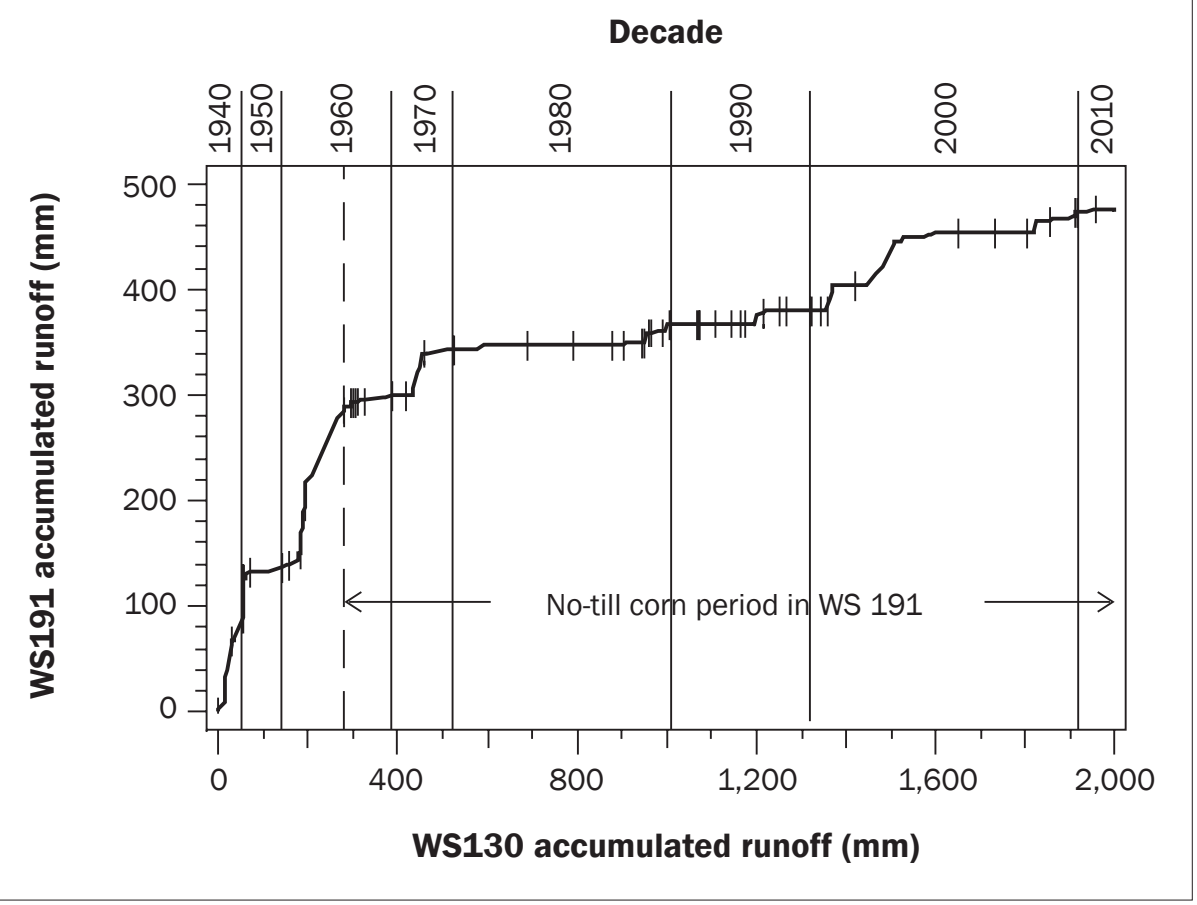

precipitation afterwards). The effectiveness of no-till to reduce runoff is apparent from figure 2 by the near horizontal trend in the curve during no-till for WS191. However, runoff production during this practice was sensitive to winter soil and weather conditions, seasons during which the largest portion of total record runoff occurs.

Curve Number Trend During No-Till at WS191. There was no trend in CNi during six time periods identified within the no-till period (5 to 12 runoff events for the periods; table 3). CNi ranged from 49.6 to 83.0, but the rank-correlation probability of 0.598 suggested that there was no trend of

$\mathrm{CNi}$ as length of time in no-till management increased (table 3). The data highlight, however, the need for long records of runoff to accurately determine $\mathrm{CN} i$ for practices that do not yield high runoff. Also, short records of $P$ and $Q$ data can lead to wide variations in CNi. The rate of change of no-till on $\mathrm{CN}$ cannot be determined; however, the double-mass curve plot (figure 2) suggested the effect was immediate for this watershed (one to two growing seasons). In this case, no-till corn production was implemented following two years of meadow. In instances where no-till is preceded by crop management practices that are more destructive to

Table 3

Investigation of possible curve number (CNi) trend during no-till at WS191.

\begin{tabular}{lllll}
\hline $\begin{array}{l}\text { Period } \\
\text { number }\end{array}$ & $\begin{array}{l}\text { Beginning } \\
\text { year }\end{array}$ & $\begin{array}{l}\text { Period } \\
\text { duration (y) }\end{array}$ & $\begin{array}{l}\text { Number } \\
\text { of events }\end{array}$ & $\mathbf{C N i}$ \\
\hline 1 & 1964 & 10 & 6 & 66.6 \\
2 & 10 & 11 & 49.6 \\
3 & 1974 & 10 & 6 & 83.0 \\
4 & 1984 & 10 & 6 & 52.7 \\
5 & 1994 & 3 & 12 & 68.5 \\
6 & 2004 & 5 & 5 & 74.5 \\
\hline & 2007 & & Rank & 0.598 \\
& & & correlation & \\
& & & &
\end{tabular}


soil structure (e.g., conventional tillage) such a rapid response will probably not be evident.

Curve Numbers for Agricultural Practices at WS191 and WS130. Sufficient data for two periods in the CWMM rotation were available for WS191: conventional corn (one year of data) and wheat. There were insufficient data during the meadow years, either because the monitoring station was not in operation or because of lack of larger events for the CN procedure. CNi for WS191 during the corn years was $90.6(66.3+24.3$; table 4 and figure $3 \mathrm{a}$ ) and decreased to 65.5 $(66.3-0.8)$ during the wheat years. The weather during the corn years limited the range of measured $\mathrm{P}$ compared with that for the other practices. The larger $\mathrm{CN}$ for the largest two $\mathrm{P}$ points in figure 3 a suggested a possible "violent" response according to Hawkins' (1993) watershed classification. However, there tended to be larger variability of $\mathrm{CN}$ for larger $P$ in other $\mathrm{CN}$ vs. $P$ graphs in the present paper, and more data are required to come to that conclusion. The larger $\mathrm{CN} i$ for conventional corn was attributed to soil surface sealing by raindrop impact and was significantly larger at the 5\% probability level compared with the other two practices. Wheat was sown in the fall, grass sown in the spring, and wheat harvested in July to August at a time when grass stand generally protected the landscape and promoted infiltration.

$\mathrm{CN} i$ for no-till was 66.3 , a $24.3 \mathrm{CN}$ unit decrease from conventional corn (table 4). The reduction was probably due to macropore formation by earthworms, higher soil organic C content, and good residue cover in WS191. Studies conducted by BlancoCanqui et al. $(2006,2007)$ on an adjacent no-till area with the same soil types demonstrated that complete corn residue removal, which in many respects should be similar to the conditions encountered with conventional tillage, resulted in reduced soil organic $\mathrm{C}$, macropore formation, and aggregate stability that contributed to a decrease in soil saturated hydraulic conductivity. The tabular NRCS handbook values for a row crop with crop residue cover in good hydrological condition on hydrological group $\mathrm{C}$ soil is 82 (NRCS 2004). WS191 has group C soils and was $16 \mathrm{CN}$ units smaller than the handbook value. No-till was not significantly different from wheat (zero fell between the $95 \%$ confidence limits of -5.4 and +3.8 ); however, the $k$ parameter was significantly

\section{Figure 3}

Ordered asymptotic curve number (CNi) plots in WS191 for (a) corn, wheat, and no-till and (b) wheat and no-till rotation and corn (units for fitting parameter $k$ are $\mathrm{mm}^{-1}$ ).

(a)

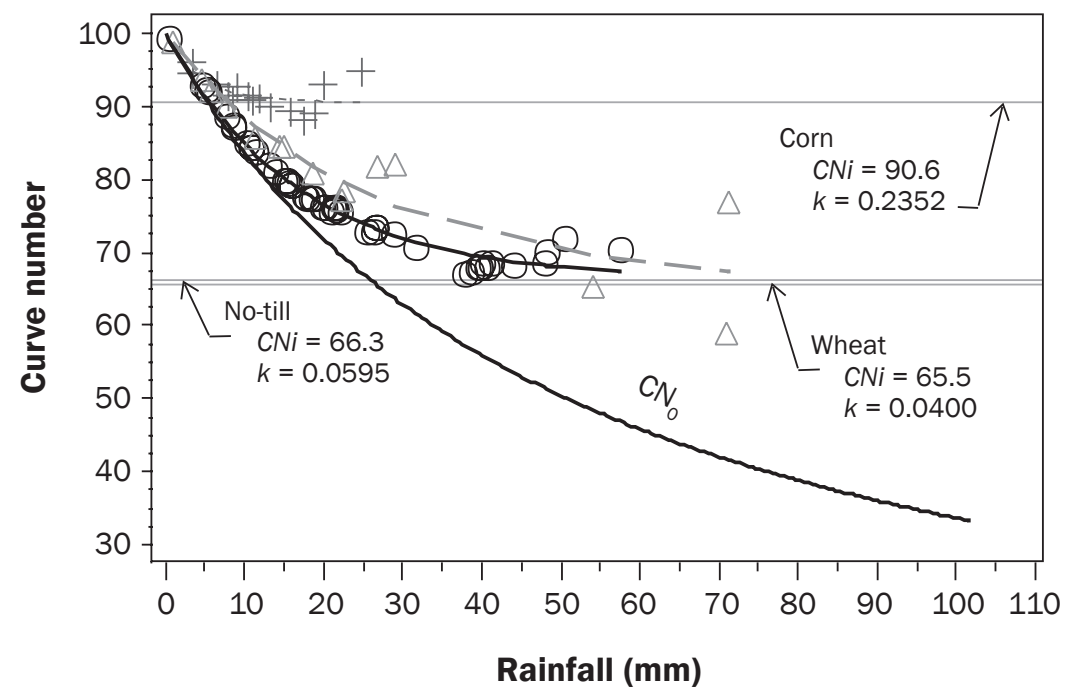

Legend

+ -Corn $\triangleq$, Wheat $\vartheta$ No-till

(b)

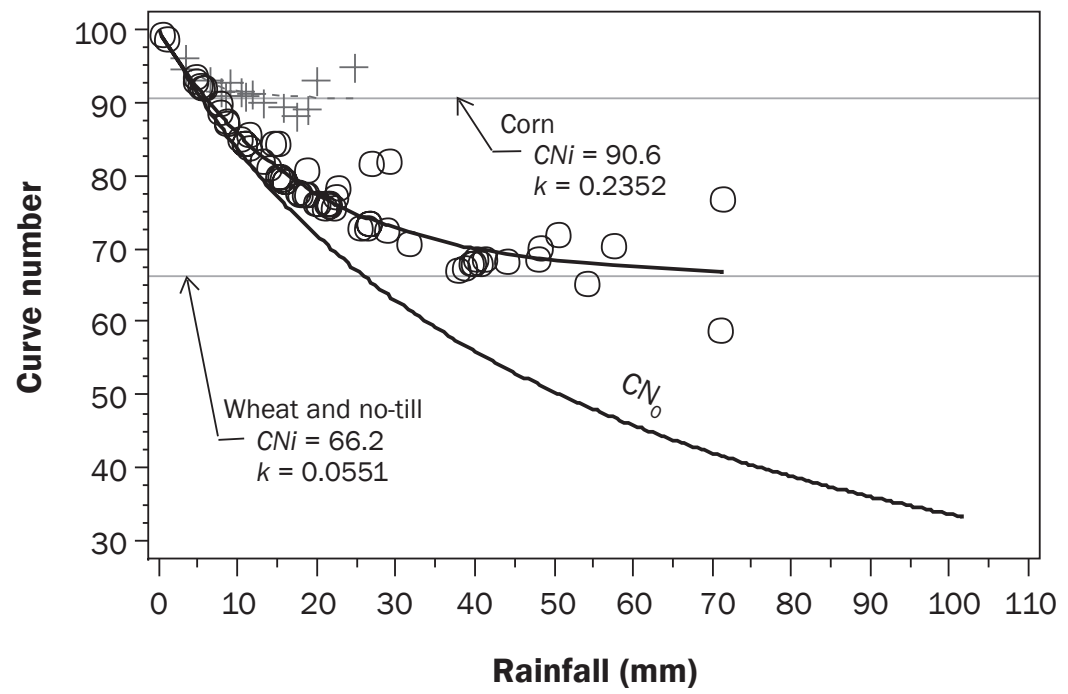

Legend

+ - Corn $€$ Wheat and no-till

smaller for wheat. Considering that wheat and no-till were the same (ignoring differences in $k$ ), a combined $C N i$ was 66.2 (table 4 and figure $3 \mathrm{~b}$ ). However, after this fitting, $k$ was similar for corn and combined wheat and no-till. No further combination of data was made due to the similar $k$. The $C N i$ of 66.3 for WS191 was larger than the $C N i$ range of 55 to 60 in the no-till $\mathrm{CN}$ study by Endale et al. (2010). CNi for WS191 is approximately $10 \mathrm{CN}$ units larger than for the Georgia watershed.

For WS130, CNi prior to 1964 was 77.3 and afterwards was 77.4 (table 4 and figure 4). Parameter $k$ for the two periods was approximately $0.0904 \mathrm{~mm}^{-1}\left(2.3 \mathrm{in}^{-1}\right)$. Neither $\mathrm{CN} i$ nor $k$ was statistically different for the two periods during the 65-year runoff record. 
Table 4

Ordered asymptotic curve number-fitting ( $\mathrm{CNi}$ ) summary for comparison between no-till, corn, and wheat on WS191 and between meadow periods on WS130 (units for $k$ are $\mathrm{mm}^{-1}$ ).

\begin{tabular}{|c|c|c|c|c|c|c|c|c|}
\hline Watershed & $\begin{array}{l}\text { Agricultural } \\
\text { practice }\end{array}$ & $\begin{array}{l}\text { Equation } 5 \\
\text { parameter }\end{array}$ & $\begin{array}{l}\text { Final } \\
\text { parameter }\end{array}$ & $\begin{array}{l}P_{\min } \\
(\mathbf{m m})\end{array}$ & $\begin{array}{l}\text { Estimated } \\
\text { parameter }\end{array}$ & $\begin{array}{l}\text { Standard } \\
\text { error }\end{array}$ & $\begin{array}{l}\text { Lower } \\
\text { confidence } \\
\text { limit }\end{array}$ & $\begin{array}{l}\text { Upper } \\
\text { confidence } \\
\text { limit }\end{array}$ \\
\hline \multirow[t]{3}{*}{191} & No-till & $\mathrm{CNi}$ & 66.3 & 34 & 66.3 & 1.1 & 64.1 & 68.4 \\
\hline & Corn & $\mathrm{CNi}$ & 90.6 & 9 & 24.3 & 1.5 & 21.4 & 27.2 \\
\hline & & k & 0.2352 & & 0.1757 & 0.1007 & -0.0251 & 0.3766 \\
\hline \multirow[t]{4}{*}{191} & No-till and wheat & $\mathrm{CNi}$ & 66.2 & 36 & 66.2 & 1.1 & 64.1 & 68.4 \\
\hline & & k & 0.0551 & & 0.0551 & 0.0040 & 0.0472 & 0.0630 \\
\hline & Corn & $\mathrm{CNi}$ & 90.6 & 9 & 24.4 & 1.6 & 21.2 & 27.5 \\
\hline & & k & 0.2352 & & 0.1801 & 0.1172 & -0.0535 & 0.4137 \\
\hline 130 & MeadowPre & $\mathrm{CNi}$ & 77.3 & 22 & 77.3 & 0.2 & 76.8 & 77.8 \\
\hline \multirow[t]{2}{*}{130} & Meadow combined & $\mathrm{CNi}$ & 77.4 & 22 & & & & \\
\hline & & $k$ & 0.0895 & & & & & \\
\hline
\end{tabular}

The combined $C N i$ was 77.4 with a combined $\mathrm{k}$ of $0.0895 \mathrm{~mm}^{-1}\left(2.27 \mathrm{in}^{-1}\right)$. The minimum precipitation above which $\mathrm{CNi}$ is applicable averaged $22 \mathrm{~mm}$ (0.87 in), but varied from 9 to $50 \mathrm{~mm}$ (0.35 to $1.97 \mathrm{in}$ ).

CNi for WS191 no-till (horizontal line at $\mathrm{CN}=66.3$ ) was $11 \mathrm{CN}$ units lower than WS130 permanent meadow during the period WS191 was in no-till (73; table 4 and figure 4). The dissimilarity in $\mathrm{CNi}$ is greater than expected because soils at WS130 were classified as having high infiltration and permeability compared with WS191 and WS128, which should have resulted in a lower CN. A counteracting factor might be the difference in average slopes; WS130 slope is 2.3 times greater than WS191 (21.7\% vs. 9.4\%). Also, Kelley et al. (1975) noted that soil in the upper part of WS130 is loamy with sandstone bedrock and no textural build up in the soil profile, suggesting high infiltration rates, but that bedrock in the lower part of the watershed is shale. The middle section of WS130 is mapped as Coshocton-Rayne soil which has much slower permeability than the adjacent soils (table 1). The topographically lower watershed characteristics may be serving to generate runoff immediately upslope from the flume more often during storms. Available soil water vs. tension curves from laboratory analyses of soil samples at three landscape positions on each watershed (figure 5) showed that for the same tension, there is a tendency for higher median soil water at WS130 at three depths sampled

\section{Figure 4}

Ordered asymptotic curve number (CNi) plots for WS130 prior to and during the no-till period on WS191 (units for fitting parameter $k$ are $\mathrm{mm}^{-1}$ ). WS191 CNi line shown for comparison with WS130.

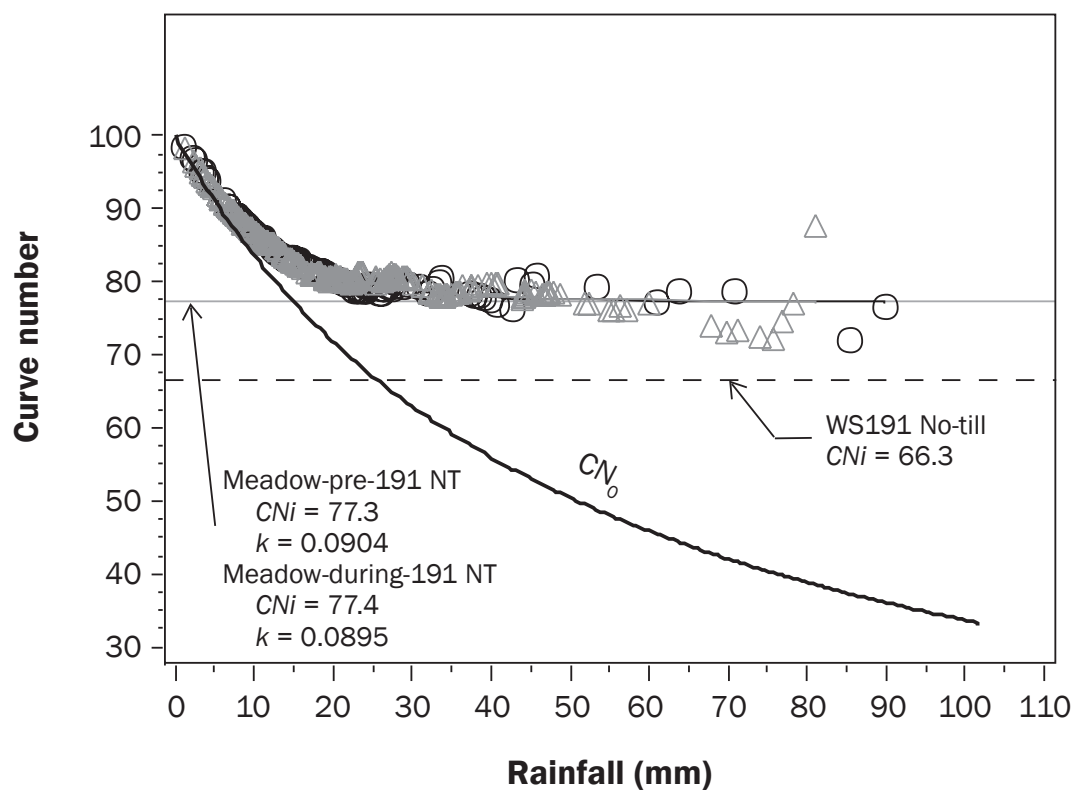

Legend

○- Meadow-pre-191 NT $\triangle$ Meadow-during-191 NT 
(Kelley et al. 1975), particularly for the top and middle soil depths. There was also a tendency for higher soil water contents at the sampling position just above the flume in the top and middle soil depths (Kelley et al. 1975). While differences were not statistically different, the trend in data was not as expected from the soil survey. Bonta (1998) also observed runoff differences in similar soil-map units due to varying soil characteristics on small NAEW experimental watersheds.

Curve Numbers for Agricultural Practices at WS128. The WS128 data suggest that the two meadow years (M1 and M2) in the CWMM rotation did not have statistically different CNs (M1 and M2 CNs were 63.6 and 60.6, respectively; table 5 and figure 6a). Parameter $k$ for M1 and M2 were 0.0432 and $0.0350 \mathrm{~mm}^{-1}(1.10$ and 0.89 $\left.\mathrm{in}^{-1}\right)$, respectively, but there were statistical differences. However, the M2 confidence interval for $k$ nearly included zero, and a difference in $k$ was considered borderline, and thus not practically significant because of a lack of interpretation of $k$. Combining the meadow data gave a $\mathrm{CNi}$ of 61.9 and $k$ of $0.0386 \mathrm{~mm}^{-1}\left(0.98 \mathrm{in}^{-1}\right)$ (figure 6b).

When the combined meadow data were compared with wheat, there was also no significant difference in $\mathrm{CNi}$, but borderline significance for $k$ (table 2 and figure 7a). Combining meadow (M1 and M2) and wheat yielded a $C N i$ of 62 and $k$ of 0.0421 $\mathrm{mm}^{-1}\left(1.07 \mathrm{in}^{-1}\right)$. Corn-mulch $\mathrm{CN} i$ was 74.6 and $k$ was $0.0669 \mathrm{~mm}^{-1}\left(1.7 \mathrm{in}^{-1}\right)$, both significantly different from corresponding values for combined meadow and wheat (figure $7 \mathrm{~b}$ ). The minimum precipitation above which CNi is applicable averaged $46 \mathrm{~mm}$ (1.81 in), but varied from 30 to $57 \mathrm{~mm}$ (1.18 to 2.24 in). There was a tendency for larger average $P_{\min }$ for the smaller $C N i$ of this site.

Curve Numbers for Wheat at WS128 and WS191. There was no statistical difference for $\mathrm{CN} i$ and $k$ between WS128 and WS191. CNi for wheat at WS191 was 65.5 and at WS128 was 61.1 (table 6 and figure $8 a)$. Corresponding $k$ values were 0.0400 and $0.0454 \mathrm{~mm}^{-1}$ (1.02 and $\left.1.15 \mathrm{in}^{-1}\right)$. Combining the wheat crop years for these two watersheds resulted in a $\mathrm{CNi}$ of 63.7 and $k$ of $0.0471 \mathrm{~mm}^{-1}\left(1.2 \mathrm{in}^{-1}\right.$ ) (table 6 and figure $8 \mathrm{~b}$ ). Pmin above which $C N i$ is applicable was $42 \mathrm{~mm}$ (1.65 in) for combined wheat, 52 $\mathrm{mm}$ (2.05 in) for combined meadow, and 34 $\mathrm{mm}(1.34 \mathrm{in})$ for no-till.

\section{Figure 5}

Soil water tension vs. percentage soil moisture for North Appalachian Experimental Watershed watersheds WS128, WS130, and WS191, for three watershed sampling points each, at three soil depths (data from Kelley et al. 1975): (a) top, 5.7 to $12.7 \mathrm{~cm}$; (b) middle, 20 to $27.7 \mathrm{~cm}$; and (c) bottom, 53.1 to $60.7 \mathrm{~cm}$.

(a)

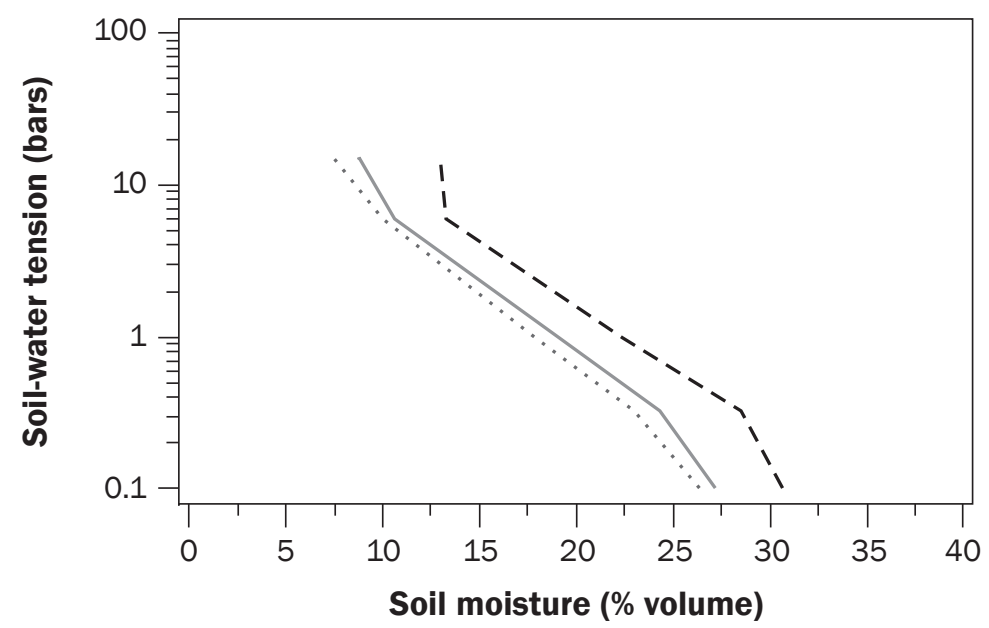

(b)

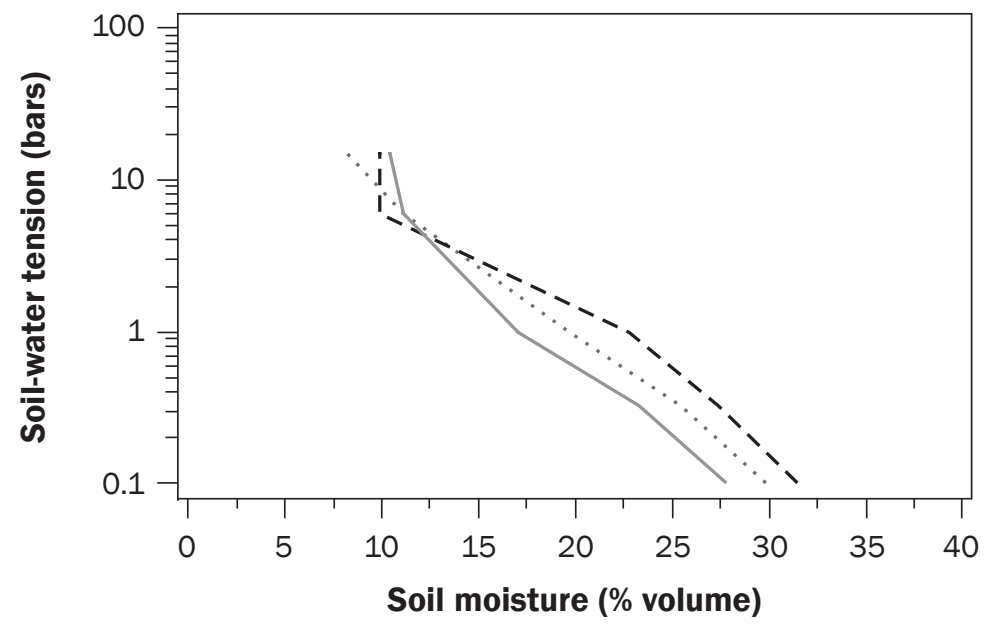

(a)

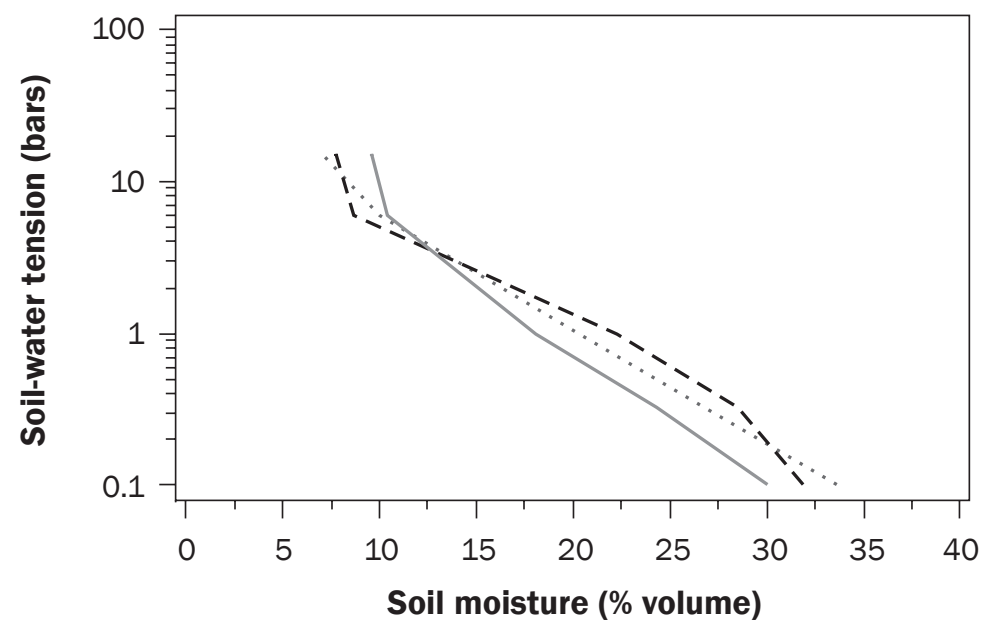

Legend

-WWS128 - - WS130 - WS191 
Table 5

Ordered asymptotic curve number-fitting ( $C N i)$ summary for comparison between meadow 1 (M1) and meadow 2 (M2), combined meadow and wheat, and combined meadow/wheat and corn on WS128 (units for $k$ are $\mathrm{mm}^{-1}$ ).

\begin{tabular}{|c|c|c|c|c|c|c|c|c|}
\hline Watershed & $\begin{array}{l}\text { Agricultural } \\
\text { practice }\end{array}$ & $\begin{array}{l}\text { Equation } 5 \\
\text { parameter }\end{array}$ & $\begin{array}{l}\text { Final } \\
\text { parameter }\end{array}$ & $\begin{array}{l}P_{\min } \\
(\mathbf{m m})\end{array}$ & $\begin{array}{l}\text { Estimated } \\
\text { parameter }\end{array}$ & $\begin{array}{l}\text { Standard } \\
\text { error }\end{array}$ & $\begin{array}{l}\text { Lower } \\
\text { confidence } \\
\text { limit }\end{array}$ & $\begin{array}{l}\text { Upper } \\
\text { confidence } \\
\text { limit }\end{array}$ \\
\hline \multirow[t]{3}{*}{128} & M1 & $\mathrm{CNi}$ & 63.6 & 46 & 63.6 & 1.2 & 61.3 & 66.0 \\
\hline & M2 & $\mathrm{CNi}$ & 60.6 & 57 & -3.1 & 1.7 & -6.4 & 0.3 \\
\hline & & k & 0.035 & & -0.0082 & 0.0032 & -0.0146 & -0.0018 \\
\hline \multirow[t]{2}{*}{128} & $\mathrm{M}$ (combined 1 and 2$)$ & $\mathrm{CNi}$ & 61.9 & 52 & 61.9 & 1.0 & 59.9 & 63.8 \\
\hline & & k & 0.0454 & & 0.0068 & 0.0026 & 0.0016 & 0.0120 \\
\hline \multirow[t]{3}{*}{128} & $\mathrm{M}(1$ and 2$)$ and & $\mathrm{CNi}$ & 62.0 & 48 & 62.0 & 0.9 & 60.3 & 63.7 \\
\hline & & k & 0.0421 & & 0.0421 & 0.0017 & 0.0387 & 0.0455 \\
\hline & Corn-mulch & $\mathrm{CNi}$ & 74.7 & 30 & 12.8 & 1.1 & 10.5 & 15.0 \\
\hline
\end{tabular}

\section{Table 6}

Ordered asymptotic curve number-fitting (CNi) summary for comparison between wheat, meadow, and no-till on WS128 and WS191 (units for $k$ are $\mathrm{mm}^{-1}$ ).

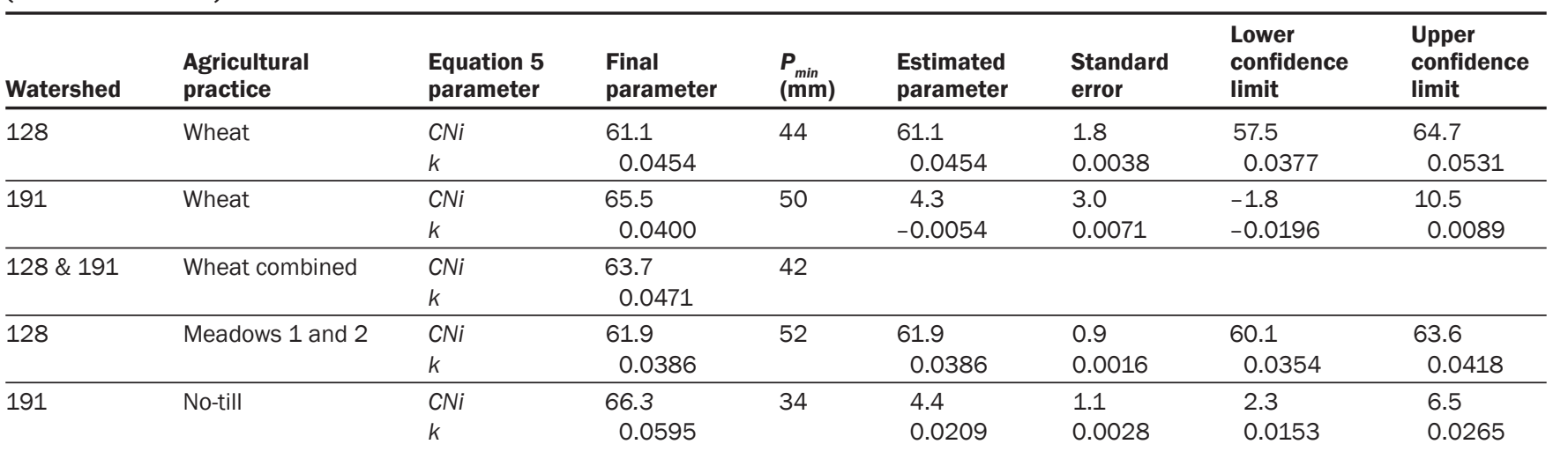

Table 7

Curve number $(\mathrm{CN})$ summary within watersheds.

\begin{tabular}{|c|c|c|c|c|c|c|c|c|c|}
\hline \multirow[b]{2}{*}{ Watershed } & \multirow[b]{2}{*}{$\begin{array}{l}\text { Agricultural } \\
\text { practice }\end{array}$} & \multirow[b]{2}{*}{$\begin{array}{l}\text { Estimated } \\
\text { NRCS } \\
\text { handbook }\end{array}$} & \multirow[b]{2}{*}{$\begin{array}{l}\text { Original } \\
\mathrm{CNi}\end{array}$} & \multirow[b]{2}{*}{$\begin{array}{l}\text { Combined } \\
\mathrm{CNi}^{*}\end{array}$} & \multirow[b]{2}{*}{$\begin{array}{l}\text { Further } \\
\text { combining } \\
\text { CNi* }\end{array}$} & \multicolumn{4}{|c|}{$\begin{array}{l}\text { CN statistics for events with } \\
\text { P > } 25 \mathrm{~mm} \text { (unordered data) }\end{array}$} \\
\hline & & & & & & $\begin{array}{l}\text { Median } \\
\text { CN } \\
\end{array}$ & $\begin{array}{l}\text { Minimum } \\
\text { CN }\end{array}$ & $\begin{array}{l}\text { Maximum } \\
\text { CN }\end{array}$ & $\begin{array}{l}\text { Number } \\
\text { of values }\end{array}$ \\
\hline \multirow[t]{3}{*}{128} & Meadow 1 & 71 & 63.6 & 61.9 & 62.0 & 70.8 & 62.2 & 82.9 & 12 \\
\hline & Meadow 2 & & 60.6 & & & 69.9 & 52.3 & 83.0 & 6 \\
\hline & Wheat & 80 & 61.1 & & & 64.0 & 54.4 & 77.4 & 8 \\
\hline \multirow[t]{2}{*}{130} & Meadow pre-NT & 58 to 71 & 77.3 & 77.4 & & 72.9 & 59.3 & 90.2 & 33 \\
\hline & Meadow during NT & & 77.4 & & & 75.2 & 46.7 & 92.9 & 87 \\
\hline \multirow[t]{3}{*}{191} & Corn & 88 & 90.6 & & & 89.0 & 74.7 & 94.7 & $6 \dagger$ \\
\hline & Wheat & 80 & 65.5 & 66.2 & & 67.9 & 54.5 & 84.3 & 5 \\
\hline & No-till & 82 & 66.3 & & & 60.4 & 52.4 & 86.8 & 18 \\
\hline
\end{tabular}




\section{Figure 6}

Ordered asymptotic curve number (CNi) plots for meadow 1 (M1) and meadow 2 (M2) land management at WS128 (units for fitting parameter $k$ are $\mathrm{mm}^{-1}$ ): (a) separate $\mathrm{CNi}$ for each meadow year and (b) combined $\mathrm{CNi}$ for both meadow years.

(a)

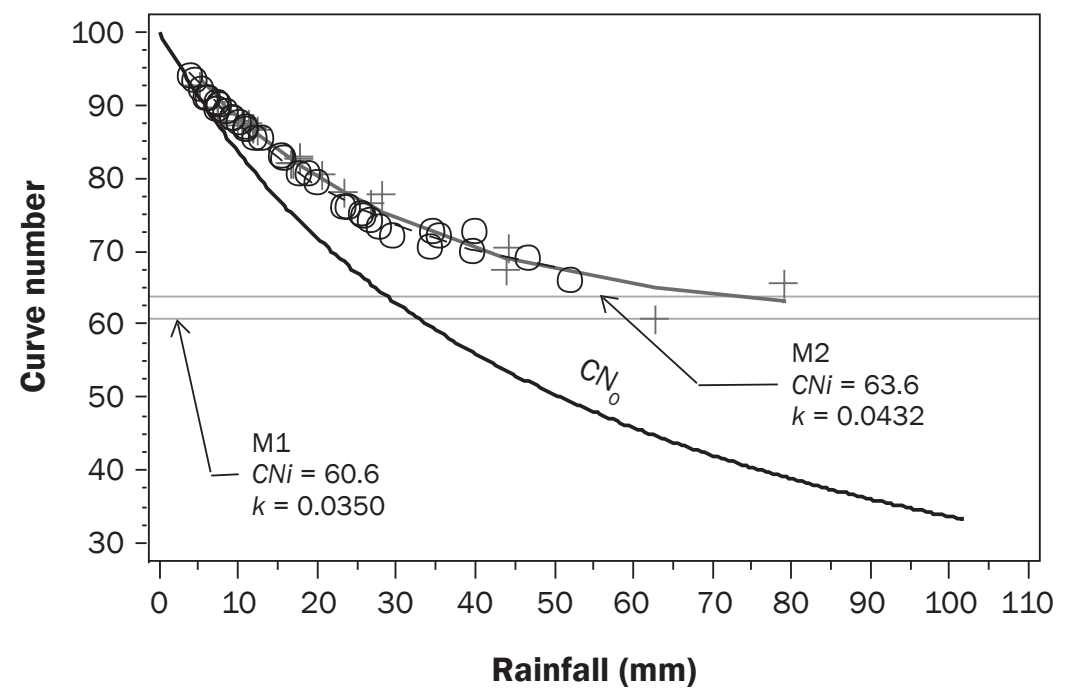

(b)

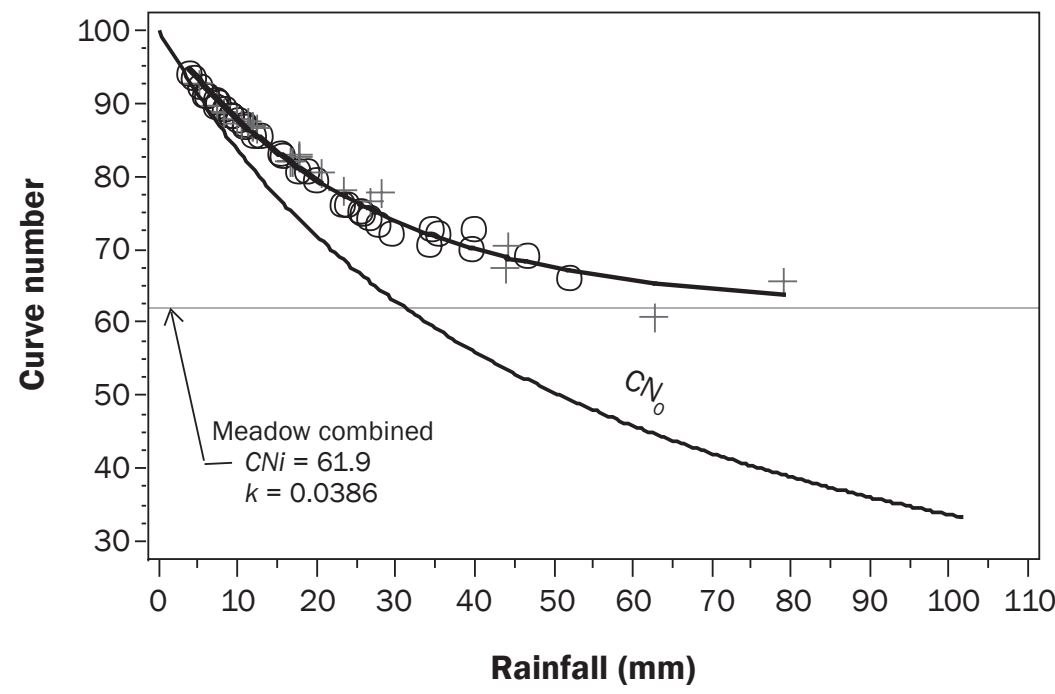

Legend

O- M1

$+\mathrm{M} 2$

Curve Numbers for Combined Meadow at WS128 and No-Till at WS191. CNi and $k$ for combined meadow at WS128 and no-till for WS191 were statistically different (table 6 and figure 9). $\mathrm{CNi}$ for combined meadow was $61.9\left(k=0.0386 \mathrm{~mm}^{-1}\left[0.98 \mathrm{in}^{-1}\right]\right)$ and for no-till at WS191 was $66.3(k=0.0595$ $\left.\mathrm{mm}^{-1}\left[1.51 \mathrm{in}^{-1}\right]\right)$. Runoff data from meadow were not available from WS191; however, the statistically similar $C N i$ values for wheat for the two watersheds (table 6), the statistically similar M1 and M2 and wheat $\mathrm{CNi}$ for
WS128 (table 5), and the similar soil characteristics (figure 5) for the two sites suggested that $\mathrm{CNi}$ for the meadow practices would be the same on the two sites. This assumption suggested that CNi for no-till on WS191 would be slightly larger than meadow in rotation (estimated difference of approximately 4.4 CN units). If runoff reduction was a goal in conservation planning, a slightly smaller runoff potential can be realized from meadow compared with continuous longterm no-till corn in hilly areas such as the
NAEW. $P_{\min }$ ranged from 34 to $52 \mathrm{~mm}(1.34$ to $2.05 \mathrm{in})$ with an average of $44 \mathrm{~mm}(1.73$ in). As with WS128, the average $P_{\min }$ was larger for the smaller $\mathrm{CN}$.

Curve Number Summaries within and across Watersheds. A summary of $\mathrm{CN} i$ values within watersheds in table 4 through table 6 is presented in table 7 along with $\mathrm{CN} i$ estimated from the NRCS handbook (NRCS 2004). Across-watershed $\mathrm{CNi}$ are summarized in table 8. Handbook $\mathrm{CNi}$ were different from field-measured values for most practices. Corn at WS191 appeared the most similar, and continuous meadow at WS130 was much larger than the handbook value. Most often the measured value was much less than that estimated from the handbook, highlighting the need for locally derived values and an understanding of the errors and variability that can be expected by using handbook values. $\mathrm{CNi}$ of approximately 60 is the minimum found in the study watersheds.

The median of unordered $\mathrm{CN}$ results (table 7) shows generally close agreement with the asymptotically determined values for nonmeadow practices (comparing "Original CNi" column with "Median CN" column). Notable differences in the table were the median $\mathrm{CN}$ for M1 and M2 for WS128 that were larger than the asymptotic values but about the same as handbook values. For WS130, median CN for the meadow periods were slightly less than $C N i$ but greater than the upper limit of handbook values for a mixture of soil types. Median no-till $\mathrm{CN}$ was less than $\mathrm{CN} i$ and notably less than handbook values.

\section{Summary and Conclusions}

An investigation of $\mathrm{CN}$ under continuous long-term no-till corn and other potentially high infiltration agricultural field-sized landscapes was conducted using experimental watershed surface runoff data from the NAEW near Coshocton, Ohio. A watershed under 48 years of continuous no-till corn (WS191) was compared with other crop management practices in its history, with another watershed having a 65-year runoff record under permanent meadow (hay production; WS130), and with a watershed adjacent to WS191 that experienced a similar pre-no-till history (WS128). Gauged watershed areas ranged from 0.49 to 1.08 ha (1.21 to $2.67 \mathrm{ac})$. Agricultural practices considered were conventional corn, wheat, and first- and second-year meadow as part of a 


\section{Figure 7}

Ordered asymptotic curve number ( $\mathrm{CNi}$ ) plot comparisons for WS128 (units for fitting parameter $k$ are $\left.\mathrm{mm}^{-1}\right)$ : (a) combined meadow $1\left(\mathrm{M}_{1}\right)$ and meadow $2\left(\mathrm{M}_{2}\right)$ and wheat and $(\mathrm{b})$ combined $\mathrm{M}_{1}$ and $M_{2}$ and wheat and corn-mulch.

(a)

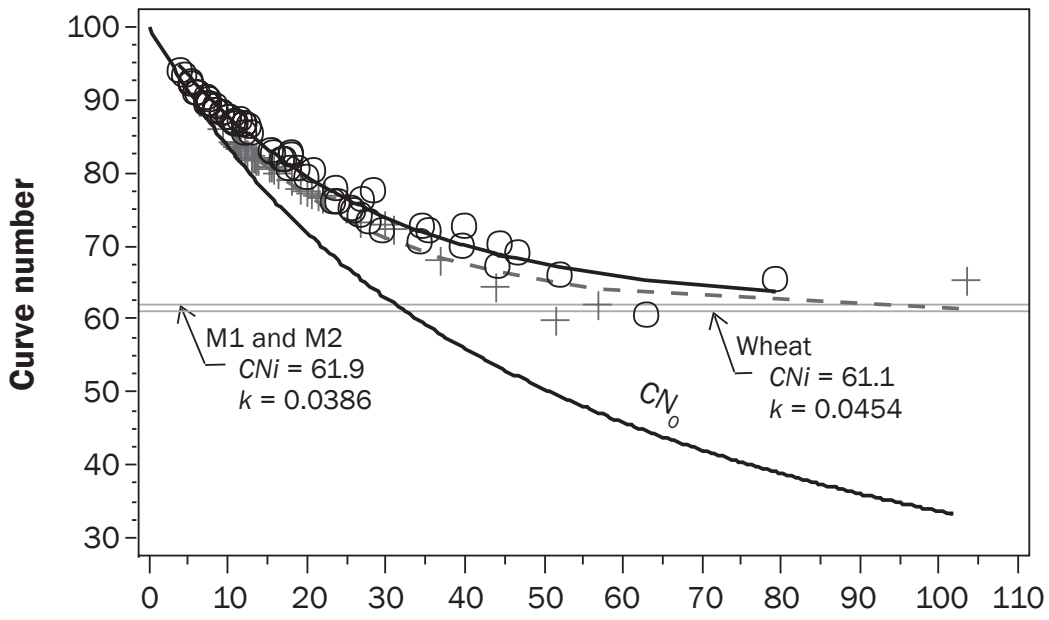

Rainfall (mm)

\section{Legend}

๑- Meadow-1 and $2 \quad-+$ - Wheat

(b)

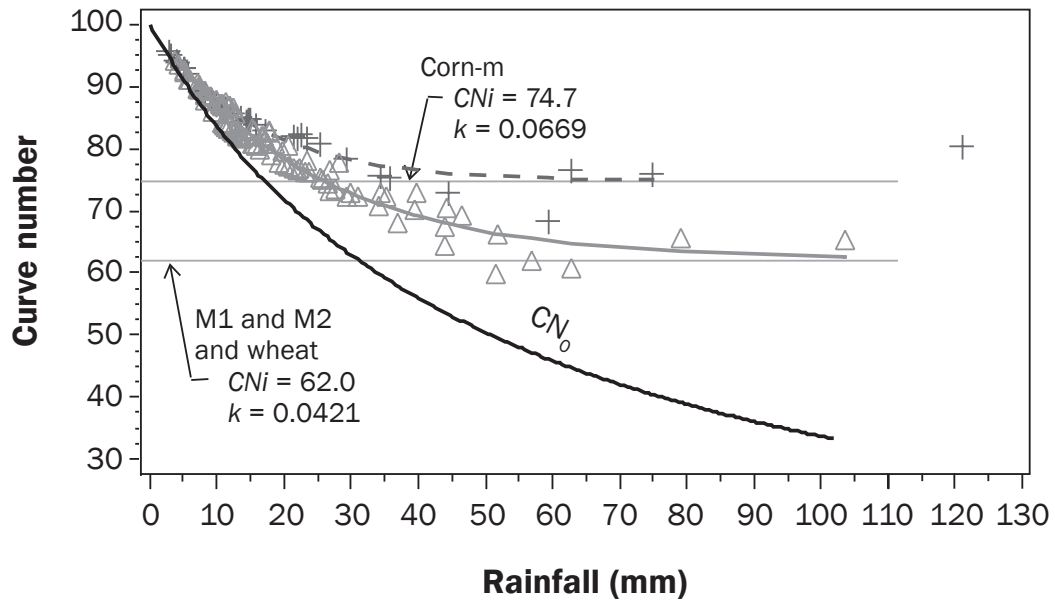

Legend

+ Corn-m $\triangle \mathrm{M} 1$ and M2 and wheat

CWMM rotation, continuous meadow, and continuous no-till corn with a worm population. Additionally, corn with a mulch-tilled culture and conventional corn were compared. Statistical comparisons, using the sum-ofsquares-reduction test (Hinds and Milliken 1987), were made between CNi (Hawkins 1993) for the different agricultural practices on the three watersheds. The following conclusions can be made in the context of soils and weather characteristics found at the NAEW:
- $\mathrm{CN} i$ for the 48-year record of continuous no-till corn practice with an earthworm population at WS191 decreased substantially to 66.3 ( $-24.3 \mathrm{CN}$ units from the period of conventional corn in a CWMM rotation on the same site). The equivalent NRCS handbook value was $16 \mathrm{CN}$ units larger at 82. Continuous no-till with a worm population and good residue cover was more effective in enhancing infiltra- tion and reducing runoff than continuous meadow in the present study.

- $C N i$ was lowest for no-till corn, and wheat and meadow in a rotation with an average of 63.4. $\mathrm{CN} i$ was surprisingly high (77.4) for a watershed in continuous meadow, was largest for conventional corn at 90.6, and about the same for corn mulchtilled culture as for meadow (74.7).

- One or two growing seasons appear to be the length of the no-till transition period when starting with meadow as the previous crop. Data from WS191 and WS130 documented the significant immediate reduction in runoff from the no-till watershed; however, there was no trend in $\mathrm{CN} i$ during the no-till period. WS191 no-till runoff production was approximately $11 \%$ of runoff from the permanent meadow on WS130.

- Runoff production under no-till was sensitive to winter soil and weather conditions and can account for a large percentage of annual runoff.

- Readily available soil maps may not be representative of actual field conditions to characterize the hydrological performance of watersheds.

- Simple grass establishment can have similar infiltration characteristics as no-till corn with a thriving population of earthworms that create macropores.

- Early in the wheat record, only manure was applied to supply nutrients, a practice used in organic agriculture. During the wheat years in the rotation, $C N i$ values were among the smallest (combined $\mathrm{CN}$ of 63.7).

- There are CN-reducing benefits by only disking the sod prior to planting corn (mulch tillage). The corn-mulch culture treatment (74.6) had a lower CNi than conventional corn (90.6) by $16 \mathrm{CN}$ units when both were in a CWMM rotation.

- Approximately one year of meadow management was all that was needed to achieve a significant reduction in $\mathrm{CN}$ after wheat in a CWMM rotation, suggesting a rapid recovery of infiltration by simple planting of grass after a disturbance of the soil surface.

- Median CN values using nonordered data were similar to asymptotically determined ordered $\mathrm{CNi}$, but could differ notably from handbook values.

- $C N i$ of approximately 60 was the lowest found. The results are applicable for areas of similar terrain, management practices, geol- 


\section{Figure 8}

Ordered asymptotic curve number (CNi) plots for wheat at WS191 and WS128 (units for fitting parameter $k$ are $\mathrm{mm}^{-1}$ ): (a) separate $C N i$ for wheat and (b) combined $C N i$ for wheat.

(a)

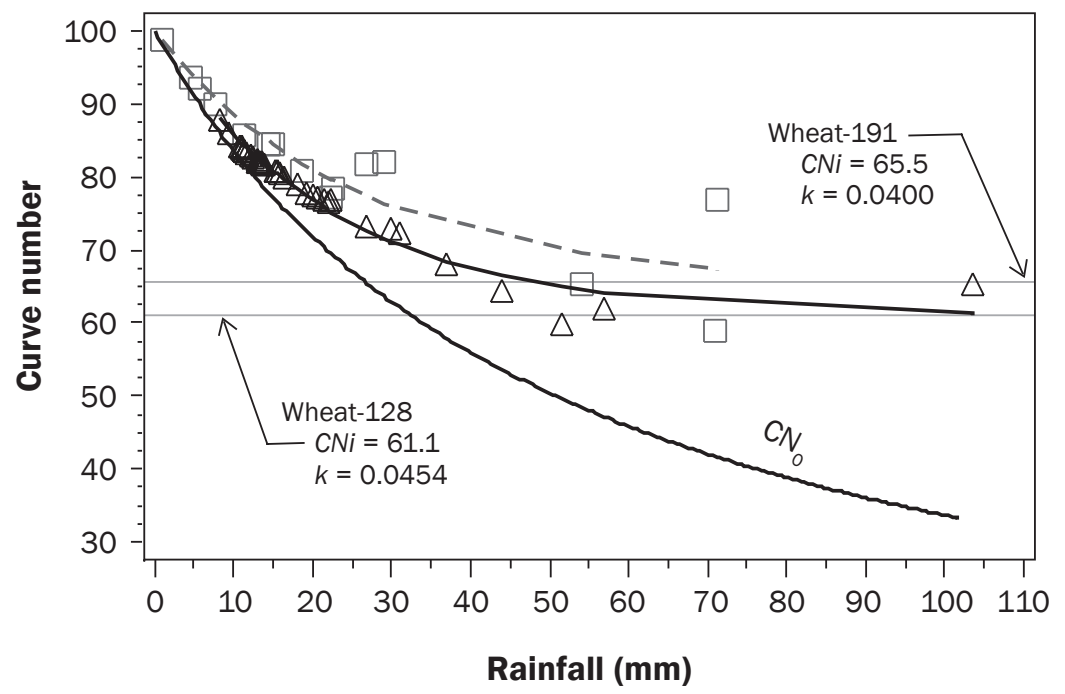

(b)

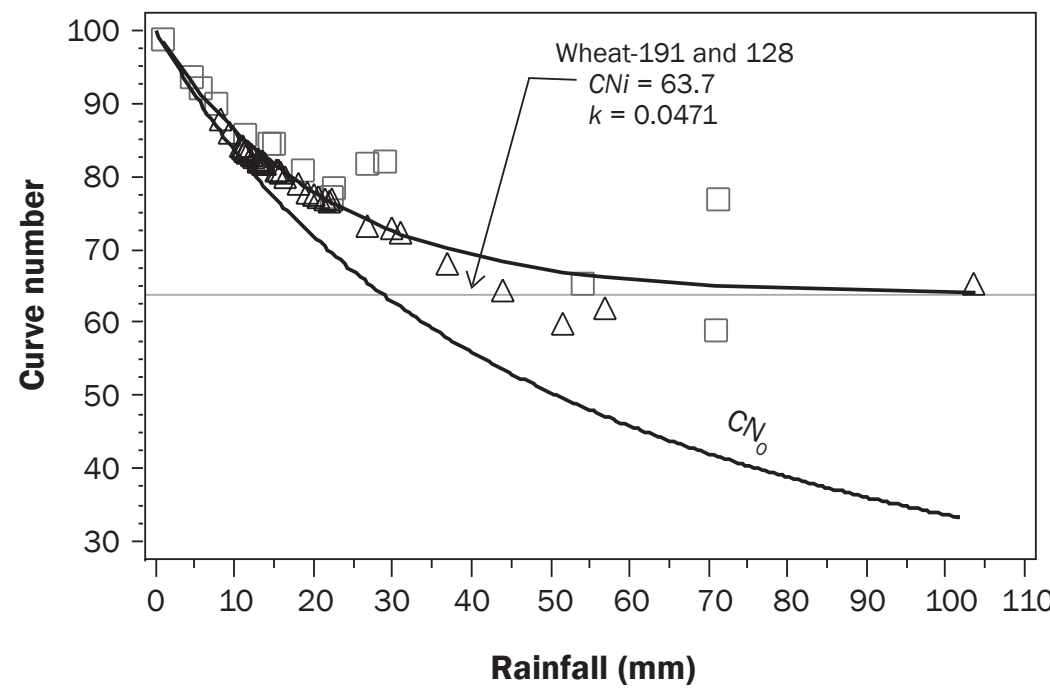

\section{Legend}

$-\square$ Wheat-WS191 $\triangle$ Wheat-WS128

\section{Table 8}

Curve number (CNi) summary across watersheds.

\begin{tabular}{llll}
\hline Watershed & $\begin{array}{l}\text { Agricultural } \\
\text { practice }\end{array}$ & Original $\mathbf{C N i}$ & Combined $\mathbf{C N i}$ \\
\hline 130 & Meadow & 77.4 & \\
191 & No-till & 66.3 & 63.7 \\
128 & Wheat & 61.1 & \\
191 & Wheat & 65.5 & \\
128 & Meadow 1 and 2 & 61.9 & \\
191 & No-till & 66.3 & \\
* Combined CNi when there were no statistical differences in CNi for across-watershed comparisons.
\end{tabular}

ogy, soils, subsoil permeability, and climate of the NAEW watersheds. Differences between handbook and measured $\mathrm{CN}$ suggest that local values are more representative than handbook values.

\section{Acknowledgements}

The author appreciates guidance on $\mathrm{CN}$ determination provided by R.H. Hawkins, professor emeritus, School of Natural Resources and Environment, University of Arizona, Tucson, Arizona, and guidance on statistics provided by Deborah Boykin, statistician, USDA Agricultural Research Service, Stoneville, Mississippi.

\section{References}

Blanco-Canqui, H., R. Lal, W.M. Post, R.C. Izaurralde, and L.B. Owens. 2006. Rapid changes in soil carbon and structural properties due to stover removal from no-till corn plots. Soil Science 171(6):468-482.

Blanco-Canqui, H., R. Lal, W.M. Post, R.C. Izaurralde, and M.J. Shipitalo. 2007. Soil hydraulic properties influenced by corn stover removal from no-till corn in Ohio. Soil \& Tillage Research 92(1-2):144-155.

Bohlen, P.J., W.M. Edwards, and C.A. Edwards. 1995 Earthworm community structure and diversity in experimental watersheds in Northeastern Ohio. Plant and Soil 170:233-239.

Bonta, J.V. 1998. Spatial variability of runoff and soil properties on small watersheds in similar soil-map units. Transactions of the American Society of Agricultural Engineers 41(3):575-585.

Brakensiek, D.L., H.B. Osborn, and W.J. Rawls. 1979. Field Manual for Research in Agricultural Hydrology. USDA, Agriculture Handbook No. 224. Washington, DC: US Government Printing Office.

Dripchack, M., and R.H. Hawkins. 1996. GETPQ96 computer program. University of Arizona, School of Natural Resources. Tucson, AZ: School of Renewable Natural Resources, Watershed Resources Program, University of Arizona.

Edwards, C.A., W.M. Edwards, and M.J. Shipitalo. 1992. Earthworm populations under conservation tillage and their effects on transport of pesticides into groundwater. Proceedings British Crop Protection Conference - Pests and Diseases 7C(16):859-864.

Edwards, W.M., L.D. Norton, and C.E. Redmond. 1988. Characterizing macropores that affect infiltration into nontilled soil. Soil Science Society of America Journal 52(2):483-487.

Endale, D.M., H.S. Schomberg, D.S. Fisher, and M.B. Jenkins. 2011. No-Till and curve numbers - A closer look. Proceedings of 2011 Georgia Water Resources Conference, held April 11-13, 2011, at The University of Georgia USDA Agricultural Research Service, J. Phil Campbell, Sr., Natural Resources Conservation Center, Watkinsville, GA 


\section{Figure 9}

Ordered asymptotic curve number (CNi) plots for no-till at WS191 and meadow 1 (M1) and meadow $2\left(\mathrm{M}_{2}\right)$ at WS128 (units for fitting parameter $k$ are $\mathrm{mm}^{-1}$ ).

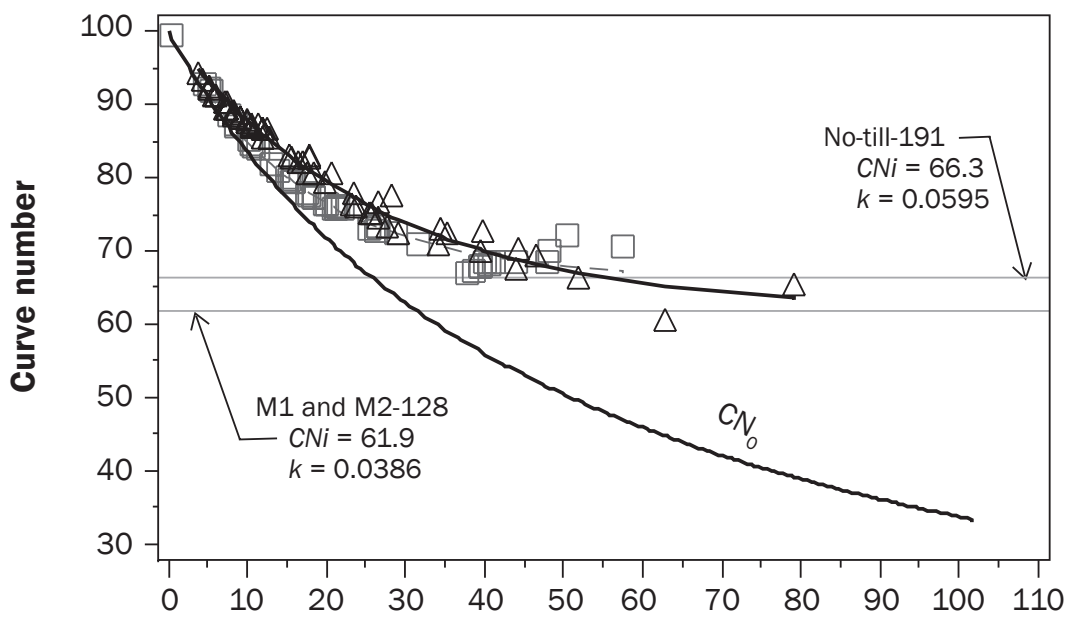

Rainfall (mm)

\section{Legend}

$-\boxminus$ No-till-WS191

Germann, P.F.,W.M. Edwards, and L.B. Owens. 1984. Profiles of bromide and increased soil moisture after infiltration into soils with macropores. Soil Science Society of America Journal 48(2):237-244.

Hawkins, R.H. 1993. Asymptotic determination of runoff curve numbers from data. Journal of Irrigation and Drainage Engineering 119(2):334-345

Hawkins R.H.,T.J.Ward, D.E.Woodward, and J.A.Van Mullem. 2009. Curve Number Hydrology: State of the Practice. Reston,VA:American Society of Civil Engineers.

Hinds, M.A., and Milliken, G.A. 1987. Statistical methods for using nonlinear models to compare silage treatments. Biometrical Journal 29:825-834.

Hudson, B.D. 1994. Soil organic matter and available water capacity Journal of Soil and Water Conservation 49(2):189-194.

Kelley, G.E., W.M. Edwards, L.L. Harrold, and J.L. McGuinness. 1975. Soils of the North Appalachian Experimental Watershed. USDA Misc. Publ. \#1296. Washington, DC: USDA Agricultural Research Service.

Maski, D., K.R. Mankin, K.A. Janssen, P. Tuppad, and G.M. Pierzynski. 2008. Modeling runoff and sediment yields from combined in-field crop practices using the Soil and Water Assessment Tool. Journal of Soil and Water Conservation 63(4):193-203, doi:10.2489/jswc.63.4.193.

NRCS (Natural Resources Conservation Service). 2004. Chapter 9 - Hydrologic Soil-Cover Complexes. Part 630 Hydrology, National Engineering Handbook. 20 pp. Washington, DC: Natural Resources Conservation Service.

SAS Institute, Inc. 2012a Version 9.3. Cary, NC: SAS. http:// www.sas.com/.

Shipitalo, M.J. 2002. Earthworms and Structure. In Encyclopedia of Soil Science, ed. R. Lal, 1255-1258. New York: Marcel Dekker Inc.
Shipitalo, M.J., and K.R. Butt. 1999. Occupancy and geometrical properties of Lumbricus terrestris L. burrows affecting infiltration. Pedobiologia 43:782-794.

Shipitalo, M.J., W.A. Dick, and W.M. Edwards. 2000. Conservation tillage and macropore factors that affect water movement and the fate of chemicals. Soil Tillage Research 53:167-183.

Shipitalo, M.J., W.M. Edwards, and C.E. Redmond. 1994. Comparison of water movement and quality in earthworm burrows and pan lysimeters. Journal of Environmental Quality 23(6):1345-1351.

Sprague, M.A., and G.B. Triplett. 1986. No-Tillage and Surface-Tillage Agriculture: The Tillage Revolution. New York:Wiley Interscience.

Triplett, G.B., Jr., and W.A. Dick. 2008. No-tillage crop production: A revolution in agriculture. Agronomy Journal 100:153-165.

USDA SCS (Soil Conservation Service). 1944. 1944 Progress Report, North Appalachian Experimental Watershed, Coshocton, Ohio. Washington, DC: USDA Soil Conservation Service.

USDA SCS. 1948.1948 Progress Report, North Appalachian Experimental Watershed, Coshocton, Ohio. Washington, DC: USDA Soil Conservation Service.

USDA SCS. 1972. National Engineering Handbook, Section 4, Hydrology. Washington, DC: USDA Soil Conservation Service.

Weyers, S.L., H.H. Schomberg, P.F. Hendrix, K.A. Spokas, and D.M. Endale. 2008. Construction of an electrical device for sampling earthworm populations in the field. Applied Engineering in Agriculture 24(3):391-397. 